\title{
Development of Walking, Swimming and Neuronal Connections after Complete Spinal Cord Transection in the Neonatal Opossum, Monodelphis domestica
}

\author{
N. R. Saunders, ${ }^{1}$ P. Kitchener, ${ }^{1}$ G. W. Knott, ${ }^{1}$ J. G. Nicholls, ${ }^{2}$ A. Potter, ${ }^{1}$ and T. J. Smith ${ }^{1}$ \\ ${ }^{1}$ Division of Anatomy and Physiology, University of Tasmania, Hobart, Tasmania 7001, Australia, and 2 Biozentrum der \\ Universität Basel, CH-4056 Basel, Switzerland
}

\begin{abstract}
Development of coordinated movements was quantitatively assessed in adult opossums (Monodelphis domestica) with thoracic spinal cords transected by (1) crushing 7-8 d after birth [postnatal days 7-8 (P7-P8)]; at 2-3 years of age, systematic behavioral tests (e.g., climbing, footprint analysis, and swimming) showed only minor differences between control $(n=5)$ and operated ( $n=10$ ) animals; and (2) cutting on P4-P6; at 1 month these opossums exhibited coordinated walking movements but were unable to right themselves from a supine position, unlike controls $(n=6)$. When tested at 2 or 6 months, they could right themselves and showed remarkable coordination, albeit with more differences from controls than after a crush. No animals with spinal cords that were crushed at P14-18 survived because of cannibalism by the mother. Morphological studies $(n=10) 3$ months-3 years after crush at 1 week showed restoration of structural continuity and normal
\end{abstract}

appearance at the lesion site. Animals with cut rather than crushed cords showed continuity but greater morphological deficits. That lesions were complete was demonstrated by examining morphology and nerve impulse conduction immediately after crushing or cutting the spinal cord in controls. After lumbar spinal cord injection of $10 \mathrm{kDa}$ dextran amine, retrogradely labeled cells were found rostral to the lesion in hindbrain and midbrain nuclei. Conduction was restored across the site of the lesion. Thus complete spinal cord transection in neonatal Monodelphis was followed by development of coordinated movements and repair of the spinal cord, a process that included development of functional connections by axons that crossed the lesion.

Key words: Monodelphis domestica; behavior after spinal injury; regeneration; response to injury; spinal cord injury; neurite outgrowth
Outgrowth of neurites in injured adult mammalian spinal cord only occurs under special experimental circumstances, such as application of trophic molecules or antibodies and implantation of fetal CNS grafts (see Schwab and Bartholdi, 1996). By contrast, regeneration is pronounced in immature mammalian CNS (Nicholls and Saunders, 1996). In most studies on injured immature spinal cord, axonal growth only occurred when part of the cord was left intact, and fibers grew around the lesion via the normal tissue rather than across the lesion (e.g., Bernstein and Stelzner, 1983; Bregman and Goldberger, 1983a; Martin and Xu, 1988; Xu and Martin, 1991; Bates and Stelzner, 1993). In young animals such as rats, fiber growth directly across a lesion in immature CNS that is accompanied by evidence of functional development and recovery has only been demonstrable when the injury has been implanted with fetal tissue (e.g., Iwashita et al., 1994) or peripheral nerve (e.g., Aguayo et al., 1991; Cheng et al., 1996). In the early chick embryo, after spinal cord transection, the cord will recover and grow, with more or less normal locomotor function when adult (Shimizu et al., 1990; Hasan et al., 1993).

In mammals we have shown in vitro that spinal cord from neonatal opossums (Monodelphis domestica) (Treherne et al.,

Received Aug. 27, 1997; revised Oct. 9, 1997; accepted Oct. 15, 1997.

This work was supported by grants from the Australian Research Council and Workers Accident Compensation Board to N.R.S., the Motor Accident Insurance Board to N.R.S., K.M.D., P.K., and G.W.K., and the Swiss National Research Fund and the Institute for Research in Paraplegia to J.G.N.

Correspondence should be addressed to Prof. N. R. Saunders, Division of Anatomy and Physiology, University of Tasmania, G.P.O. Box 252-24, Hobart, Tasmania 7001, Australia.

Copyright (C) 1997 Society for Neuroscience $\quad 0270-6474 / 97 / 180339-17 \$ 05.00 / 0$
1992; Nicholls and Saunders, 1996) or embryonic rats [embryonic days 15-16 (E15-E16)] (Saunders et al., 1992) recovers nerve impulse conduction across a complete spinal lesion 4-5 d after the lesion; this recovery involves growth of neurites across the lesion, at least some of which are regenerating from damaged axons (Varga et al., 1995b).

Studies of functional recovery are limited in the in vitro CNS preparation (Varga et al., 1996), because it only survives for $\sim 14$ d. For longer periods, in any of the known eutherian species used for spinal repair experiments, it would be necessary to operate in utero. This problem can be overcome by using a marsupial species. When born, most of their CNS is extremely immature (Saunders et al., 1989; Krause and Saunders, 1994; Saunders, 1997). Terman et al. (1996) and Wang et al. (1996) have shown in the opossum, Didelphis virginiana, that after transection of the thoracic spinal cord in neonates both dorsal spinocerebellar and fasciculus gracilis axons grow directly through the lesion but not when the animals are $>12 \mathrm{~d}$ old. In preliminary studies we have shown that neonatal Monodelphis with spinal cord transections will survive until adulthood and will show a remarkable degree of normal locomotor function (Saunders et al., 1994, 1995).

Here we have analyzed in detail locomotor behavior of adult Monodelphis that were operated on in the first week of life to produce a complete spinal cord lesion, compared with control unoperated animals. Electrophysiological and morphological studies of the spinal cord in these animals were also made. Complete transection of the spinal cord in the first week of life in Monodelphis was followed by fiber growth across the lesion, with 


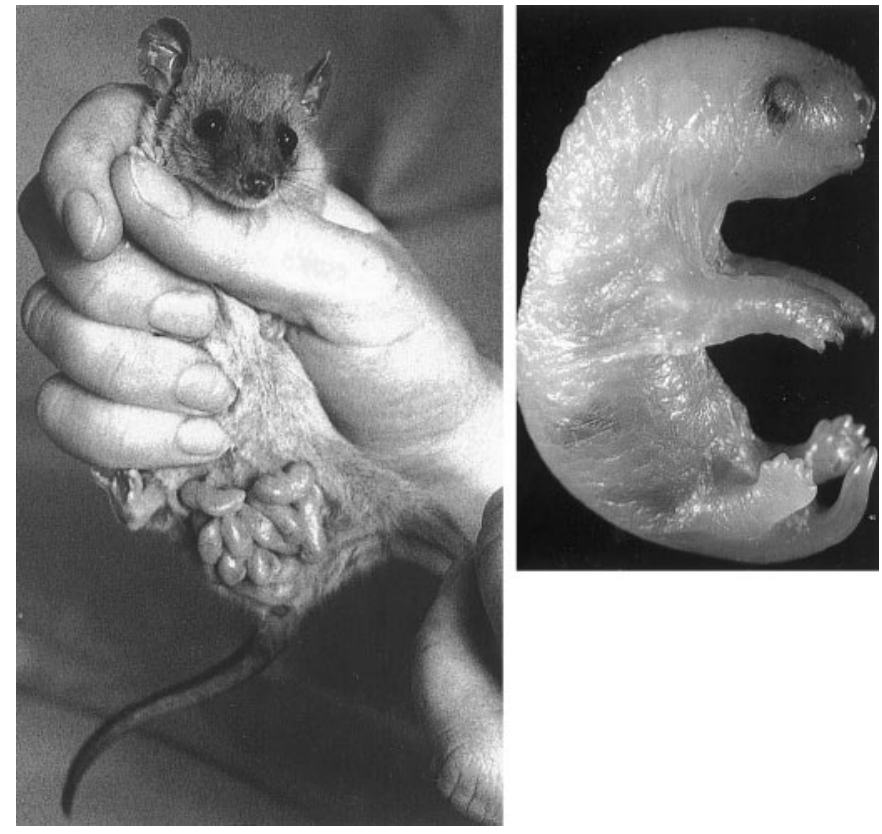

Figure 1. Left, Adult Monodelphis together with a litter of neonates at P7, which was the age at which most animals were operated on. Adult females weigh $\sim 110 \mathrm{gm}$. Right, P7 animal at higher magnification; crownrump length, $15 \mathrm{~mm}$.

substantially normal development of spinal cord structure, impulse conduction, and locomotor behavior.

\section{MATERIALS AND METHODS}

\section{Breeding and management of Monodelphis}

General descriptions of colony management for Monodelphis have been published previously (Fadem et al., 1982; Saunders et al., 1989). The Hobart colony was established from breeding pairs transferred from the colony established in Southampton, UK (Saunders et al., 1989). In the Hobart colony, animals for breeding are held in pairs in rat boxes made of colored polycarbonate, at an ambient temperature of $27^{\circ} \mathrm{C}$ and a light/dark cycle of 14/10 hr. Females are paired with fertile males for $13 \mathrm{~d}$, after which they are separated, and the females are provided with plastic nesting boxes placed within the rat boxes and filled with strips of paper. The animals are fed cat food, meat meal, high-protein cereal, Veanavite, and Avi-Drops daily, Whiskettes $4 \mathrm{~d}$ per week, bananas $3 \mathrm{~d}$ per week, and meal worms once a week. Water is provided from standard animal bottles ad libitum. Breeding in the animal house occurs all year round, although seasonal breeding has been reported recently for wild Monodelphis in their normal habitat (Bergallo and Cerqueira, 1994). Litter size is between 3 and 12 . The young animals remain tightly and almost continuously attached to the teats from the day of birth until $\sim 15$ $\mathrm{d}$ later, after which they become detached for increasing periods as they grow older and more independent. They are weaned at 55-60 d after birth and achieve their adult body weight of $90-110$ gm by $\sim 100 \mathrm{~d}$ of age (Fig. 1).

\section{Spinal cord operations}

These were performed at two ages: neonatal opossums aged postnatal days 4-8 (P4-P8) (Table 1, Fig. 1$)$ and P14-P18 $(n=18)$. The litter size was generally $6-10$. The mothers were anesthetized with intraperitoneal sodium pentobarbitone $(1 \mathrm{ml} / 100 \mathrm{gm}$ body weight of $6 \mathrm{mg} / \mathrm{ml}$ sodium pentobarbitone); the young animals were given additional inhaled Metofane as required. The anesthetized mother was placed ventral surface upward and covered with sterile drapes, apart from the pouchless area of the anterior abdominal wall to which the young animals are attached to the mother by her teats. Operations were performed as rapidly as possible, because it was found in the early stages of these experiments that many of the young animals were eaten by the mother as she recovered from the anesthetic. Shortening the period of anesthesia and feeding the mother with meal worms immediately on recovery from anesthesia al- lowed an adequate number of the operated young animals to survive. The operation in the neonates consisted of a transverse incision through the skin at the level of T1-T2 followed by either a crush by forceps or a transection made with ophthalmic scissors through the skin incision, which aimed to disrupt the whole cross-section of the spinal cord via the dorsal surface of the developing vertebral column. Crushes were maintained for $10 \mathrm{sec}$. The effectiveness of the lesion (crush or cut) was checked in one or more of the following ways.

The tips of the forceps or ophthalmic scissors were passed through the site of the lesion viewed under an operating microscope to check the completeness of the lesion. To confirm the effectiveness of the lesioning technique, some operated young animals, at the time of operation or 24 $\mathrm{hr}$ later, were reanasthetized and exsanguinated, and their cords were either removed for electrical impulse conduction studies or fixed for histology (see below). This was done in the early part of the study for some whole litters to check on the consistency of the lesions. Once the procedure was established, one operated young animal was removed at random, at or shortly after operation, for histological examination. All operations were performed by one person (N.R.S.); the removal of one animal for morphological evaluation of the lesion was made by someone else. In addition, most animals were checked either at the time of operation or on the following day by a light nociceptive stimulus applied to the hindlimbs. This usually evoked a local reflex, confined to the lower limbs; providing the lesion was complete, it did not result in any response from the upper limbs or upper part of the animal above the level of the lesion, in contrast to the controls, which did show such responses. In most cases, all of the young animals in a single litter were operated on; in some cases alternate young animals were operated on. After initial trials, we did not use sham operations involving skin lesions; because the mother tends to remove any kind of mark by licking the young animal, it is extremely difficult to distinguish operated from sham-operated animals if both have skin lesions. Attempts to suture the skin wound were counterproductive, because the mother almost always removed the suture material. In fact, the wounds healed within $48 \mathrm{hr}$, generally with limited scarring (as reported previously for this species in the neonatal period by Armstrong and Ferguson, 1995), and we saw no signs of infection in any of the operations performed. After operation, some young animals were examined for electrophysiological conduction of impulses across the crush and evidence of histological growth of fibers through the crush at periods of 1-2 hr to 3-4 weeks after operation. The remaining animals with crush lesions were observed for behavioral performance at 1,2, and 3 weeks after crush and at 3 months after crush; some animals at each of these ages were terminally anesthetized, and their spinal cords were fixed for morphological studies (see Table 1). Ten of the animals with spinal cords that had been crushed at P7-P8 were maintained until 2-3 years of age and compared with five controls. Other animals with spinal cords that had been cut at P4-P6, rather than crushed, were maintained until 2 months of age ( $n=3$ compared with $n=3$ controls) or 6 months $(n=$ 3 ; controls, $n=3$; Table 1). Systematic behavioral analysis was performed on the adult (crush) and 6 month (cut) animals using protocols that included those recommended by the American Paralysis Association (1994) as described below. These animals were then terminally anesthetized, and morphological and/or electrophysiological studies were performed (see below).

\section{Behavioral testing}

Some litters and controls were observed two to three times weekly, from shortly after operation until after weaning ( $\sim 60 \mathrm{~d}$ postnatal). Their general behavior and locomotor abilities were compared with those of controls of the same age and noted. Video recordings of their movements were made.

Comprehensive behavioral studies were performed on animals with complete crush or cut lesions of the spinal cord: (1) animals with spinal cords transected by cutting at P4-P6 were studied at weaning ( 2 months) and when they were young adults (6 months old); and (2) animals with cords that had been transected completely by crushing at P7-P8 were studied when adult (2-3 years old). The behavioral studies were performed as follows.

Locomotor abilities were assessed using tests recommended by the American Paralysis Association (1994). These are based on the detailed descriptions of such tests by Bregman and Goldberger (1983a,b), Goldberger et al. (1990), Kunkel-Bagden and Bregman (1990), and KunkelBagden et al. (1992, 1993).

The range of movements that operated animals were capable of compared with controls was assessed using the tests described briefly below. 
Table 1. Summary of spinal cord operations on Monodelphis domestica, indicating postnatal age at operation (day of birth $=\mathrm{P} 0$ ), nature of spinal lesion (crush or cut), and age at time of study

\begin{tabular}{|c|c|c|c|c|c|c|c|}
\hline \multirow[b]{2}{*}{ Postnatal age at operation (d) } & \multirow[b]{2}{*}{ Operation } & \multirow{2}{*}{$\begin{array}{l}\text { Age at time } \\
\text { of study }\end{array}$} & \multirow[b]{2}{*}{$n$} & \multicolumn{4}{|c|}{ Methods } \\
\hline & & & & $\mathrm{B}$ & $\mathrm{E}$ & $\mathrm{M}$ & $\mathrm{P}$ \\
\hline $5-8$ & Crush & P5-P9 (+0-24 hr) & 25 & & 11 & 18 & \\
\hline $6-7$ & Cut & P6-P8 (+0-24 hr) & 13 & & & 13 & \\
\hline \multirow[t]{2}{*}{6} & Cut & 2 months & 3 & 3 & & 3 & \\
\hline & Controls & 2 months & 3 & 3 & & & \\
\hline \multirow[t]{2}{*}{$7-8$} & Crush & 3 months & 8 & & & 8 & \\
\hline & Controls & 3 months & 3 & & & 3 & \\
\hline \multirow[t]{2}{*}{4} & Cut & 6 months & 3 & 3 & & 1 & 1 \\
\hline & Controls & 6 months & 3 & 3 & & 2 & \\
\hline \multirow[t]{2}{*}{$7-8$} & Crush & $2-3$ years & 10 & 10 & 5 & 8 & 3 \\
\hline & Controls & 3 years & 8 & 5 & 3 & 5 & 2 \\
\hline
\end{tabular}

Methods of study: B, behavior; E, electrophysiology; M, morphology; P, pathway tracing (dextran amine injections); $n$, number of animals. Numbers in Methods column refer to the numbers of animals and preparations studied by the methods indicated; in some cases more than one method was applied to some preparations. A further 19 animals (P11-P27 at time of study) were used for electrophysiology studies of crush preparations (see Table 2).

Observers were unaware of the condition of the animal whose performance they were scoring.

Training. Animals were trained to cross runways and grids and to climb a narrow beam for food reward. Animals were not fed on the day of training or testing and then were rewarded with meal worms after each trial. After the trial they were fed their usual meal.

Beam climbing. The animals climbed a narrow circular section beam, which was $1.2 \mathrm{~m}$ long, $20 \mathrm{~mm}$ in diameter, and placed at an angle of $45^{\circ}$ (see Fig. 4). The time it took to climb to the top and the number of errors made by the right and left hind feet while climbing were recorded. Each climb was videotaped, and this was used to assess the ability of the animal to perform this task. Each animal climbed the beam 10 times. The means and SEMs for the time to climb and number of errors for each animal were calculated (see Fig. 5); the means and SEMs for the groups of operated and control animals were also calculated (see Tables 3 and 4).

Grid. Two grid sizes were used. Both grids were $600 \mathrm{~mm}$ long but had differing gaps between the bars: 15 and $35 \mathrm{~mm}$. The time taken to cross the grid and the number of errors made during the crossing were recorded using a videotape and were analyzed later (see Fig. 4). Each animal traversed each grid 10 times. The means and SEMs for the time to cross the grid and number of errors for each animal were calculated (see Fig. 5); the means and SEMs for the groups of operated and control animals were also calculated (see Tables 3 and 4).

Runway. The runway was $1.2 \mathrm{~m}$ long and $60 \mathrm{~mm}$ wide with an inkwell at one end and a dark box containing meal worms at the other. The animals' hind feet were inked, and footprints were made on a paper insert on the bottom of the runway. Each animal repeated each "run" 10 times. The footprint analysis used was that described by Kunkel-Bagden and Bregman (1990) and de Medinaceli et al. (1982) (modified) and is summarized below and illustrated in Figure 2. Key results are summarized in Tables 3 and 4.

Distance to opposite foot (TOF) was measured from the tip of one foot to the tip of the other. Control animals were defined as "normal TOF" (NTOF) and operated as "experimental TOF" (ETOF), The mean TOF for each animal was obtained from the 10 trials. Print length (PL) was measured from the length of the print (NPL, normal PL; EPL, experimental PL), and the mean for each was calculated. Toe spreading (TS) was the distance measurement taken from the first to the fifth toe and averaged for normal (NTS) and experimental (ETS) animals. Distance between intermediary toes (IT) was the mean distance measured from the second and fourth toes for normal (NIT) and experimental (EIT) animals.

All of these measurements were then used in an equation to give an indication of the overall degree of normal function. This is called the sciatic functional index (SFI):

$$
\begin{aligned}
\mathrm{SFI} & =\frac{\mathrm{ETOF}-\mathrm{NTOF}}{\mathrm{NTOF}}+\frac{\mathrm{NPL}-\mathrm{EPL}}{\mathrm{EPL}} \\
& +\frac{\text { ETS }- \text { NTS }}{\mathrm{NTS}}+\frac{\mathrm{EIT}-\mathrm{NIT}}{\mathrm{NIT}} \times \frac{220}{4} .
\end{aligned}
$$

This is an empirically derived formula (de Medinaceli et al., 1982) that assumes that all four tests are equally important; the weighting factor is used to give an average of $100 \%$ deficit as a result of total nerve destruction.

Zero percent $( \pm 11 \%)$ represents normal function; any value below $-11 \%$ indicates a loss of function; and $-100 \%$ represents a total loss of function (de Medinaceli et al., 1982).

Kunkel-Bagden and Bregman (1990) devised an additional three measurements as part of the footprint analysis. These were also used.

Base of support is the mean measured distance between the central pads of the hind feet. Limb rotation is the mean angle formed by the intersection lines from the left and right prints. Stride length is the mean distance measured between consecutive prints on the same side (left or right).

In addition to the above well established tests for function in animals with spinal cord lesions, we also used swimming tests to obtain information about locomotor performance in the absence of the normal cutaneous and proprioceptive input from the limbs to the spinal cord, because this has been shown to be important for local limb movement rhythm generators in spinal preparations (Grillner and Wallen, 1985; Rossignol, 1996).

Swimming. A tank measuring $1.2 \mathrm{~m}$ long and $600 \mathrm{~mm}$ wide was used for this test. Individuals swam the tank length seven times, and the mean and SEM for each animal and the group means and SEMs were calculated. One control animal could not be tested, because it proved to be a nonswimmer.

Swim plus climb. The same tank was used, without the partition, but an island was placed at one end. Each animal was required to swim the length of the tank to the island and climb out of the water. The time recorded included the time it took to swim to the island and climb out. Once again individuals swam the tank length seven times, and the mean and SEM for each animal and the group means and SEMs were calculated.

Other tests. Placing, both proprioceptive and contact, and hopping tests were not possible to perform, because no means could be found to discourage Monodelphis from holding onto either the handler's hand or to their own opposite foot instead of to the bench top as required by the test.

\section{Morphological studies}

Spinal cords from immature animals were fixed for light microscopy by immersion in Bouin's solution (overnight at room temperature) or in $4 \%$ paraformaldehyde in $0.1 \mathrm{M}$ phosphate buffer $(\mathrm{PB}, \mathrm{pH} 7.2)$ overnight at $4^{\circ} \mathrm{C}$ before vibratome sectioning (see below). Adult animals were terminally anesthetized with an intraperitoneal injection of sodium pentobarbitone $(0.1 \mathrm{ml} / 100 \mathrm{gm}$ body weight of $60 \mathrm{mg} / \mathrm{ml})$ and then perfused immediately via the left ventricle over a $15 \mathrm{~min}$ period with $200 \mathrm{ml}$ of $\mathrm{PB}$ $\left(0.1 \mathrm{M}, \mathrm{pH} 7.2\right.$ at $20^{\circ} \mathrm{C}$ containing, $2000 \mathrm{IU}$ of sodium heparin) followed by $500 \mathrm{ml}$ of $4 \%$ paraformaldehyde in $0.1 \mathrm{M} \mathrm{PB}, \mathrm{pH} 7.2$ at $4^{\circ} \mathrm{C}$. After perfusion, the head and spinal cord (enclosed in the skull and vertebra) were separated from the animal and post-fixed for $24 \mathrm{hr}$ in the same fixation solution. This was stored at $4^{\circ} \mathrm{C}$ in PBS $(0.1 \mathrm{M}, \mathrm{pH} 7.2)$ until further analysis. In some adult preparations the spinal cord was dissected 


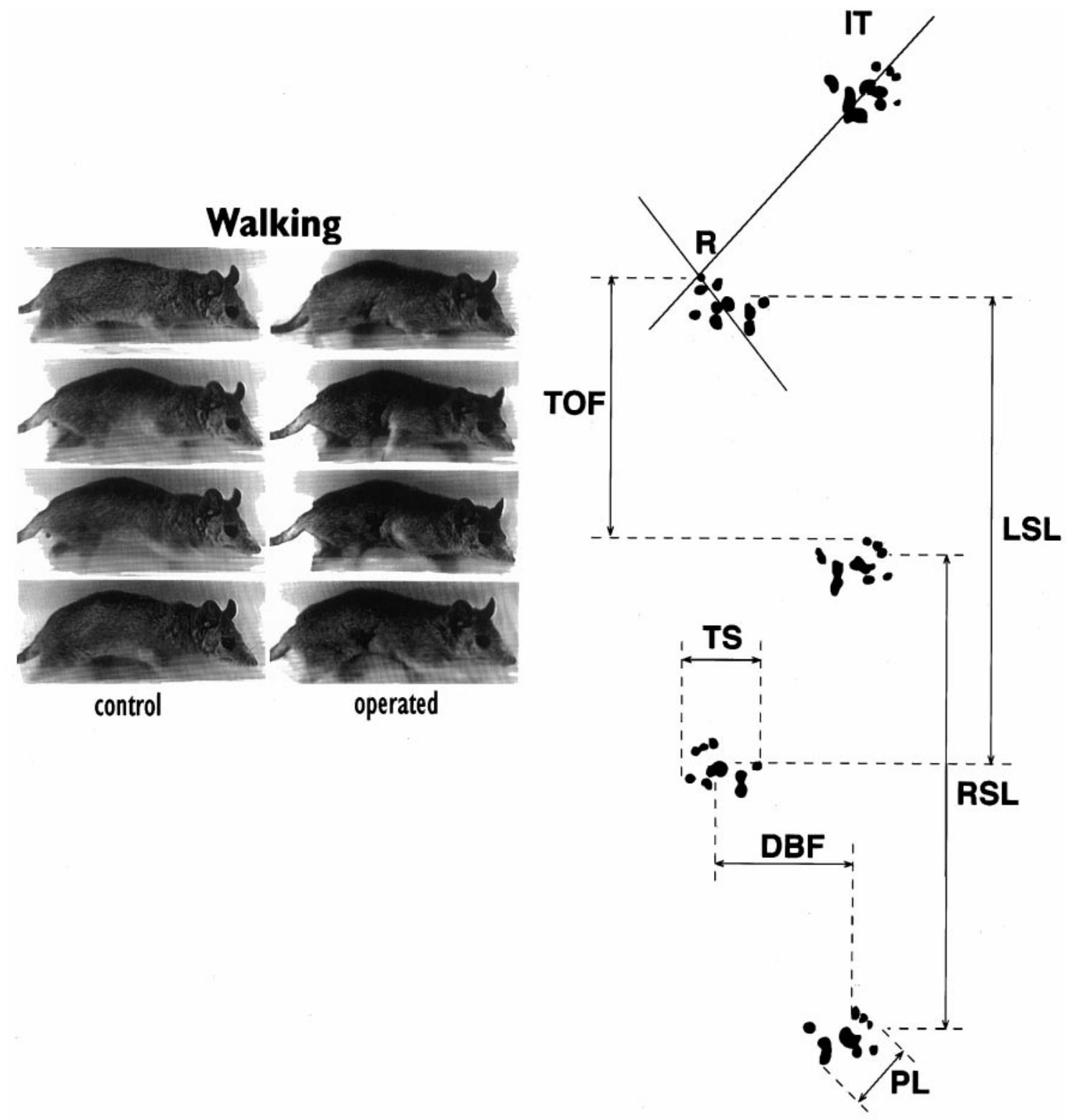

Figure 2. Left, Control and operated (crush) animals walking in the runway used for "footprint" analysis. The feet are partly obscured by the edge of the runway. Walking patterns were quantitatively assessed by the use of footprint analysis (right), as described by de Medinacelli et al. (1982) and Kunkel-Bagden and Bregman (1990) and modified as outlined in Materials and Methods. A typical pattern of hindlimb footprints and the measurements made are illustrated. $P L$, Print length; $T S$, toe spread; $I T$, distance between intermediary toes; TOF, distance to opposite foot; $D B F$, base of support; $L S L$, left stride length (i.e., distance between consecutive left hindfoot prints); $R S L$, right stride length; $r$, rotation. Results from animals with crush lesions are summarized in Table 3 and Figure 5, and results from cut lesions are summarized in Table 4 and Figure 5.

free of the vertebral column after initial fixation; in others the spinal cord was left in situ, and bone was decalcified using Fastcal decalcifier (Histo Labs). Bouin's-fixed material was washed briefly in tap water, dehydrated in graded alcohols, cleared in chloroform, and embedded in paraffin wax Serial sections of $2-20 \mu \mathrm{m}$ were cut in either transverse or longitudinal planes. Sections were stained with hematoxylin and eosin or by a silverstaining method (Sievers and Munger, 1965).

\section{Spinal pathways in operated animals}

Injection of dextran amines. Previously spinal-operated adult animals were anesthetized with an intramuscular injection of sodium pentobarbitone $(60 \mathrm{mg} / \mathrm{ml}, 0.175 \mathrm{ml} / 100 \mathrm{gm}$ body weight). Using a high-speed drill with a small $(1$-mm-diameter) sterilized drill bit, a tiny portion $(2 \times 1$ $\mathrm{mm}$ ) of the vertebra overlying the midline of the spinal cord was exposed at T12, taking care not to puncture the covering dura. Using a $5 \mu \mathrm{l}$ syringe (Hamilton) with a glass micropipette attached (tip diameter,
$40-50 \mu \mathrm{m}), 1.0-1.4 \mu \mathrm{l}$ of $25 \%$ tetramethylrhodamine-labeled dextran amine (Fluororuby, catalog \#D-1817; Molecular Probes, Eugene, OR; molecular weight, 10,000$)$ in $2.5 \%(\mathrm{v} / \mathrm{v})$ Triton X-100 diluted in $0.1 \mathrm{M}$ Tris buffer, $\mathrm{pH}$ 9.0, was injected directly into the spinal cord. This dye mixture was injected slowly over $\sim 60 \mathrm{sec}$. Throughout this procedure no CSF leaked through the dura, and there did not appear to be any significant spread of dye out into the subdural space. After injection a small piece of absorbable gelatin foam (Gelfoam) was placed over the dura before the skin was sutured. Animals were allowed to recover and returned to the colony for $7 \mathrm{~d}$ before further study. The animals were then reanasthetized with sodium pentobarbitone $(60 \mathrm{mg} / \mathrm{ml}, 0.1 \mathrm{ml} / 100 \mathrm{gm}$ body weight) and perfused with $0.1 \mathrm{M} \mathrm{PB}$ and $4 \%$ paraformaldehyde fixative as described above. Brains and spinal cords were removed and post-fixed in the same fixative for at least $24 \mathrm{hr}$, after which they were embedded in 5\% agarose and cut in either coronal or sagittal planes at $70 \mu \mathrm{m}$ on a vibratome. Sections were placed in $0.1 \mathrm{M}$ PBS, $\mathrm{pH} 7.2$, mounted onto 
glass slides in an aqueous mounting medium (Faramount; Dako, High Wycombe, UK), and viewed under a microscope (BX50; Olympus Optical, Tokyo, Japan) with appropriate fluorescence optics.

\section{Electrical recording}

To check for the functional completeness of the lesion and to document the recovery of conduction in the first 2-3 weeks after operation in vitro, CNS preparations were set up as described previously (Nicholls et al., 1990). The entire CNS was dissected out from an exsanguinated young animal under ice-cold Eagle's basal medium (Life Technologies, Grand Island, $\mathrm{NY}$ ) bubbled with $5 \% \mathrm{CO}_{2}$ in $\mathrm{O}_{2}$. For electrical stimulation and recording, preparations were maintained at room temperature, and the brain was removed from the preparation at the level of the upper brainstem, and suction electrodes were applied to each end of the spinal cord. The rostral electrode was used for stimulation, and the caudal end was used for recording. Chlorided silver wires were placed in the bath as indifferent electrodes. Signals were amplified with a differential amplifier (AC3; Almost Perfect Electronics, Basel, Switzerland) displayed on a storage oscilloscope and recorded on paper. When recordings were made from injured preparations, the electrodes were positioned with one above and one below the crush site at distances of several millimeters relative to the crush. For testing the survival and viability of crushed preparations, recordings were made at different positions along the cord with both electrodes either above or below the site of the crush.

In the adult control animals and those that had been operated on in the neonatal period (see above), to test for conduction through the crush site and in controls at the same spinal cord level, stimuli were applied to the sciatic nerve by hook electrodes $(6 \mathrm{~V}, 0.1 \mathrm{msec}, 1 / \mathrm{sec})$. Recordings were made from spinal cord at the level of $\mathrm{C} 2-\mathrm{C} 3$ after a laminectomy and from the surface of the parietal cortex after the skull and dura mater had been removed. The recording electrode consisted of a silver wire $(500$ $\mu \mathrm{m}$ in diameter) sealed into the tip of a microelectrode with epoxy. The electrode tip was ground on a fine stone until the wire, the epoxy, and the glass formed a smooth surface that made excellent electrical contact with CNS tissue. The indifferent electrode was placed in contact with tissue close to the recording electrode. Signals were amplified on a preamplifier (Almost Perfect Electronics) with filters set at $30 \mathrm{~Hz}$ and $10 \mathrm{kHz}$. Signals, which were large enough to observe on single sweeps, were averaged on a MacLab computer (Macintosh Classic II computer with MacLab Mark III attached). Routinely 32, 64, or 128 evoked potentials were averaged. In some experiments the polarity was reversed halfway through the run. Stimuli were also applied to the cerebral cortex or spinal cord while recording from the sciatic nerve. Recordings remained stable for many hours and were remarkably reproducible from preparation to preparation.

\section{RESULTS}

\section{Effectiveness of the lesion}

A preliminary series of operations was performed to establish an effective crush technique that severed the spinal cord of neonates completely. Electrophysiological evidence for the effectiveness of the lesion was obtained by using stimulating and recording suction electrodes attached to the ends of the isolated cord, as described in Materials and Methods. In 11 operated (crush) cords tested for nerve impulse conduction across the lesion at $0-24 \mathrm{hr}$ postoperatively (Table 2), nine showed no evidence of conduction; in the other two cords, which were tested at the beginning of the series, there were only tiny action potentials (i.e., clearly distinct from background noise), compared with the much larger amplitude of those recorded with both stimulating and recording electrodes rostral to the lesion. Morphological examination (see below) was performed in six of these preparations. All six spinal cords showed apparently complete disruption at the site of the lesion (Fig. 3); i.e., as far as could be detected in microscopical examination of serial sections through the lesions, no continuity of cord structure could be detected. As a control of the effectiveness of the crush (or cut) procedure in later experiments, one animal was selected randomly from the operated litter by someone other than the operator; this neonate was terminally anes-
Table 2. Conduction of action potentials across crush lesion of spinal cord at different times after making the lesion in postnatal animals aged P5-P8

\begin{tabular}{lcll}
$\begin{array}{l}\text { Postnatal age } \\
\text { at operation (d) }\end{array}$ & $\begin{array}{l}\text { Age at time } \\
\text { of study }\end{array}$ & $\begin{array}{l}\text { No. } \\
\text { conducting }\end{array}$ & $\begin{array}{l}\text { No. not } \\
\text { conducting }\end{array}$ \\
\hline $5-6$ & P5-P7 & 2 & 9 \\
$6-7$ & P11-P16 & 2 & 6 \\
$7-8$ & P21-P27 & 5 & 6
\end{tabular}

Spinal cords were dissected out from exsanguinated animals and tested as described in Materials and Methods. The potentials recorded in the two animals still conducting within $24 \mathrm{hr}$ of crushing were just distinguishable from background noise. Histological examination was carried out in six of the cords tested at $0-24 \mathrm{hr}$ after the lesion. All showed complete disruption of the cord at the site of crushing.

${ }^{a}$ These animals were from the group of 25 P5-P8 animals listed in Table 1.

thetized, exsanguinated, and examined morphologically for evidence of the effectiveness of the crush or cut. As a further check on the crush procedure all six neonates in one litter were prepared for morphological examination shortly after operation. All these animals were found to have complete spinal cord lesions (Fig. 3). All cut spinal cords showed complete separation of the two ends of the spinal cord (Fig. 3).

\section{Behavioral studies}

The American Paralysis Association (1994) recommends using multiple sensitive quantitative methods when the recovery of sensory function and motor behavior of specific body parts can be assessed. The results of the tests are summarized in Tables 3 and 4; some of the individual tests are illustrated in Figures 2 and 4. Figure 2 shows consecutive frames from a video recording of an operated animal and a control animal while walking in the runway used for footprint analysis. In general, operated animals walked normally and without apparent difficulty, although minor abnormalities in gait were noticeable in some animals. When present these took the form of a tendency to higher stepping than seen in controls and a rolling movement of the pelvis. None of the animals operated at P14-P18 $(n=18)$ survived for more than a few days; all were eaten by the mother.

\section{Behavior of adult animals with spinal cord lesions (crush) made at P7-P8}

Systematic behavioral tests were performed in 10 adult animals with spinal cords that had been crushed at P7-P8. These were compared with five adult controls.

\section{Beam climbing}

Animals climbing the beam are illustrated in Figure 4. Results from individual animals are shown in Figure 5, and mean values for operated and control animals are given in the legend to Figure 5. Any apparent differences were not statistically significant (Fig. 5 legend). Even after training each animal seemed to have a different way of climbing the beam; e.g., some "hugged" the beam, and others ran up it. Most of them seemed to make good use of their prehensile tail by wrapping it around the beam. This made it difficult to quantify the number of errors that the animals made. Kunkel-Bagden et al. (1993) found that rats also differ in their methods of climbing a beam and concluded that the ability to do so is dependent on the method of an individual and does not reflect the severity of the spinal injury. The range of individual performance in this test is shown in Figure 5.

\section{Grid}

Examples of video frames from this test are shown in Figure 4. There was no significant difference between the control and 

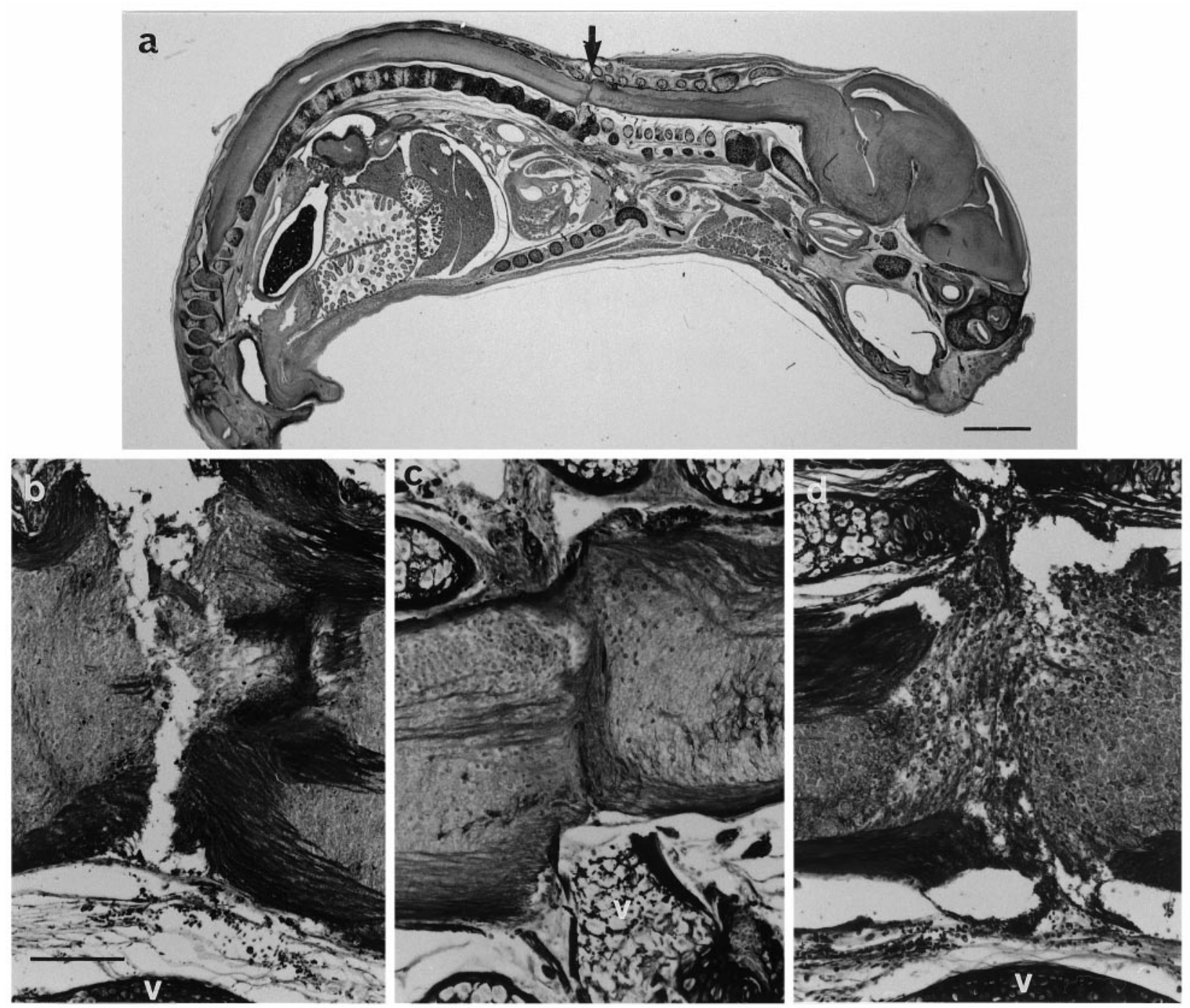

e

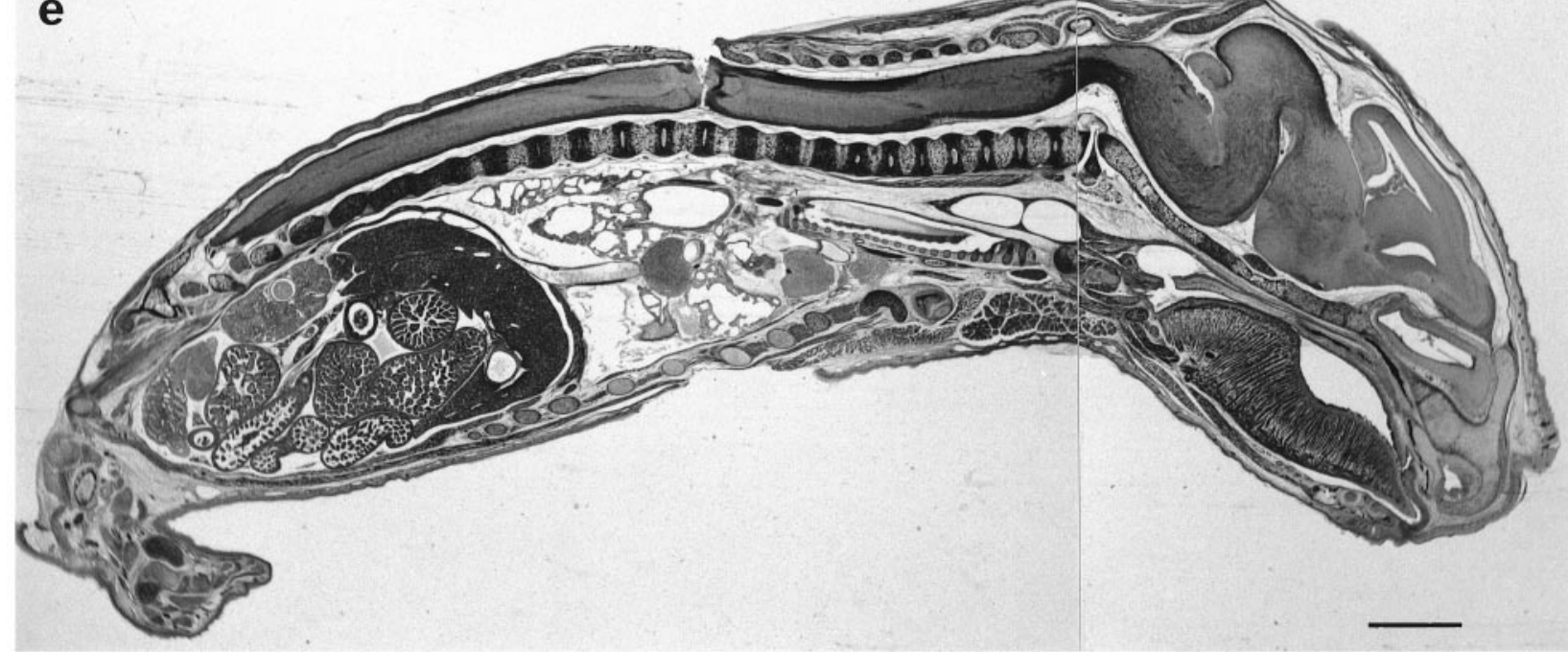

Figure 3. Typical examples of spinal cord lesions made in neonatal Monodelphis. These sections were prepared from animals that were terminally anesthetized within $1 \mathrm{hr}(a-c, e)$ or $24 \mathrm{hr}(d)$ of operation, and their spinal cords were removed for morphological examination as described in Materials and Methods. $a$, Low-power magnification of sagittal section of a P6 Monodelphis with a crush lesion of the spinal cord. The lesion is shown at higher magnification in $c$. Note that not only was the spinal cord lesion complete, but the crush was sufficiently deep to also disrupt the vertebral body at the level of the lesion [arrow in $a$; and note disrupted vertebral body $(v)$ in $c$ ]. This was apparent in many of the crushes examined histologically. $e$, Low-power sagittal section of a P7 Monodelphis with the cord transected by a cut. The lesion is illustrated at higher magnification in $b$. $d$, Crush lesion 24 hr after operation. Scale bars: $a, e, 1 \mathrm{~mm} ; \mathrm{b}, 100 \mu \mathrm{m} ; b-d$ are at same magnification. 
Table 3. Summary of quantitative data from behavioral testing of Monodelphis with spinal cords that had been completely transected by crushing at P7-P8 $(n=10)$ compared with unoperated controls $(n=4-5)$

\begin{tabular}{|c|c|c|c|c|}
\hline & \multicolumn{2}{|c|}{$\begin{array}{l}\text { Control } \\
(n=4-5)\end{array}$} & \multicolumn{2}{|l|}{$\begin{array}{l}\text { Crushed } \\
(n=10) \\
\end{array}$} \\
\hline & Mean & SEM & Mean & SEM \\
\hline \multicolumn{5}{|l|}{ Runway } \\
\hline Stride length $(\mathrm{cm})$ & 11.8 & 0.6 & 10.2 & 0.2 \\
\hline Base of support $(\mathrm{cm})$ & 3.1 & 0.1 & 2.8 & 0.2 \\
\hline Print length $(\mathrm{cm})$ & 1.5 & 0.04 & $1.3^{*}$ & 0.01 \\
\hline Toe spread $(\mathrm{cm})$ & 1.6 & 0.04 & $1.5^{* *}$ & 0.03 \\
\hline \multicolumn{5}{|l|}{$1.5 \mathrm{~cm}$ grid } \\
\hline Time (secs) & 3.3 & 0.7 & 3.0 & 0.4 \\
\hline Total errors HL & 0.9 & 0.4 & $1.5^{* * *}$ & 0.2 \\
\hline Total errors FL & 0.7 & 0.3 & 0.4 & 0.1 \\
\hline \multicolumn{5}{|l|}{$3.5 \mathrm{~cm}$ grid } \\
\hline Time (secs) & 2.5 & 0.4 & 3.7 & 0.4 \\
\hline Total errors HL & 0.7 & 0.4 & $1.6^{* * * *}$ & 0.5 \\
\hline Total errors FL & 0.3 & 0.04 & 0.3 & 0.1 \\
\hline \multicolumn{5}{|l|}{ Swim + climb } \\
\hline Time (sec) & 4.3 & 0.7 & 4.3 & 0.3 \\
\hline
\end{tabular}

After training each animal performed each test 10 times ( 7 times in the case of swimming tests), and the mean values were calculated (illustrated for some of the tests in Fig. 5). Here are presented the means and SEMs for all the control and for all the operated animals for the runway, grid-crossing, and swim + climb tests. For the runway tests the number of animals was $n=5$ for the controls. For the other tests $n=4$ animals for controls because one control animal died (cause not determined), except for the swimming tests in which the control $n=3$, because one animal was unable to swim. Most differences between control and operated groups were not statistically significant. For this reason footprint analysis values for rotation, distance to opposite foot and distance between intermediary toes are not given. Note that the base of support did not change significantly. Mean values for the beam climb and swimming tests are given in the legend to Fig. 5. The only measures that showed significant differences between control and operated animals were print length $\left({ }^{* *} p<0.05\right)$ and toe spread $\left({ }^{*} p<0.005\right)$. The significance level between the forelimb (FL) and hindlimb (HL) mean errors in the operated animals is indicated by ${ }^{* * *} p<0.002 ; * * * * p<0.04$

Table 4. Summary of quantitative data from behavioral testing of 6-month-old Monodelphis with spinal cords that had been transected completely by cutting at P4 $(n=3)$ compared with unoperated controls of the same age $(n=3)$

\begin{tabular}{|c|c|c|c|c|}
\hline & \multicolumn{2}{|c|}{$\begin{array}{l}\text { Control } \\
(n=3)\end{array}$} & \multicolumn{2}{|l|}{$\begin{array}{l}\text { Cut } \\
(n=3)\end{array}$} \\
\hline & Mean & SEM & Mean & SEM \\
\hline \multicolumn{5}{|l|}{ Runway } \\
\hline Stride length $(\mathrm{cm})$ & 15.6 & 0.2 & 12.0 & 1.3 \\
\hline Base of support $(\mathrm{cm})$ & 2.8 & 0.2 & 2.6 & 0.2 \\
\hline \multicolumn{5}{|l|}{ Narrow beam } \\
\hline Time (sec) & 3.0 & 0.5 & $8.7^{*}$ & 1.7 \\
\hline Total errors & 0.1 & 0.1 & 0.9 & 0.5 \\
\hline \multicolumn{5}{|l|}{$1.5 \mathrm{~cm}$ grid } \\
\hline Time (sec) & 1.7 & 0.3 & $3.1^{*}$ & 0.2 \\
\hline Total errors HL & 0.7 & 0.3 & $1.5^{* *}$ & 0.2 \\
\hline Total errors FL & 0.7 & 0.2 & 0.4 & 0.3 \\
\hline \multicolumn{5}{|l|}{$3.5 \mathrm{~cm}$ grid } \\
\hline Time (sec) & 1.8 & 0.2 & $4.0^{* * *}$ & 0.2 \\
\hline Total errors HL & 0.6 & 0.3 & $1.6^{*}, * *$ & 0.2 \\
\hline Total errors FL & 0.6 & 0.2 & 0.2 & 0.1 \\
\hline \multicolumn{5}{|l|}{ Swim + climb } \\
\hline Time (sec) & 2.4 & 0.06 & 4.0 & 0.7 \\
\hline
\end{tabular}

After training each animal performed each test 10 times (7 times for swimming), and the mean values were calculated (illustrated for some of the tests in Fig. 5). Here are presented the means and SEMs for all the control and for all the operated animals. None of the differences between control and operated in the runway footprint analysis was statistically significant; only stride length and base of support are shown. The operated opossums were significantly slower at climbing the beam and crossing both grids but did not make more errors than the controls. However, as with the animals with crush lesions (Table 3 ), there was a significant difference in error rate between forelimbs (FL) and hindlimbs (HL) of the operated animals when crossing the grids. ${ }^{*} p<0.05$; *** $p<0.01$ for differences between control and operated animals. **Significance level between the mean errors of the hind and forelimbs in the operated animals $(p<0.015)$. 


\section{a Narrow beam}
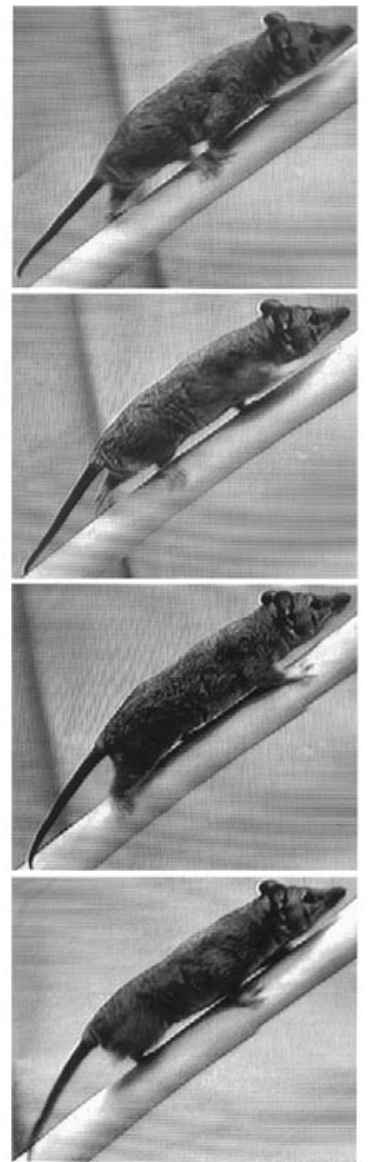

control
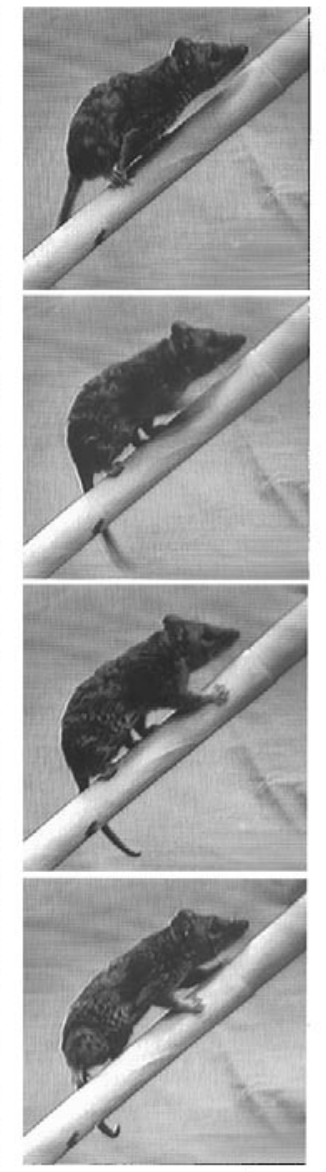

operated

\section{b Grid}
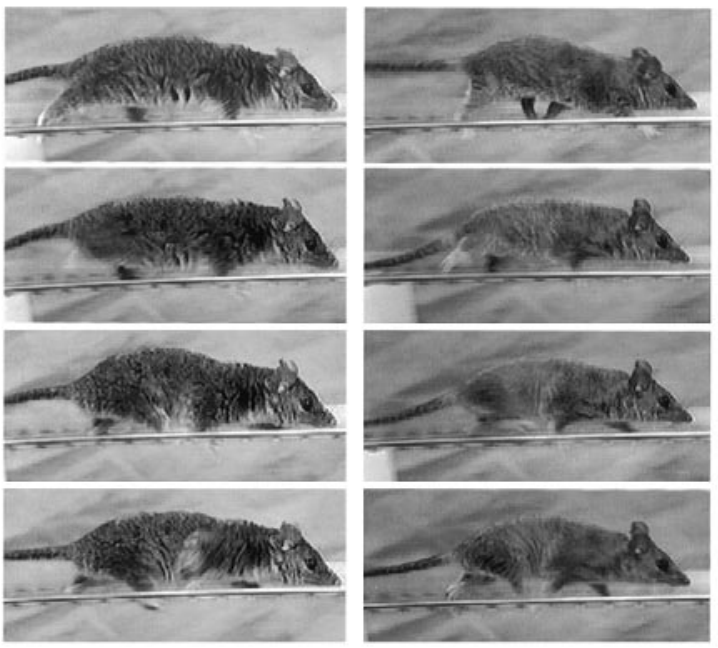

\section{c Swimming}
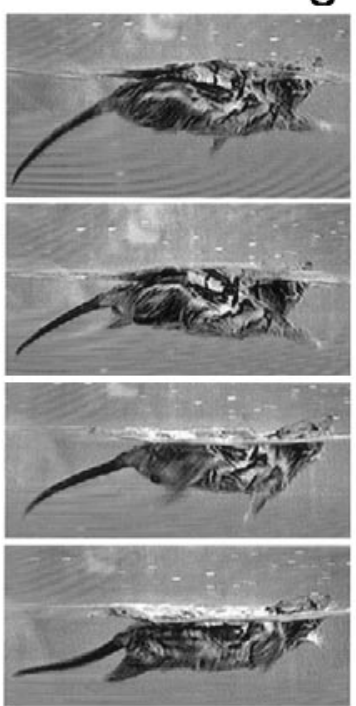

control
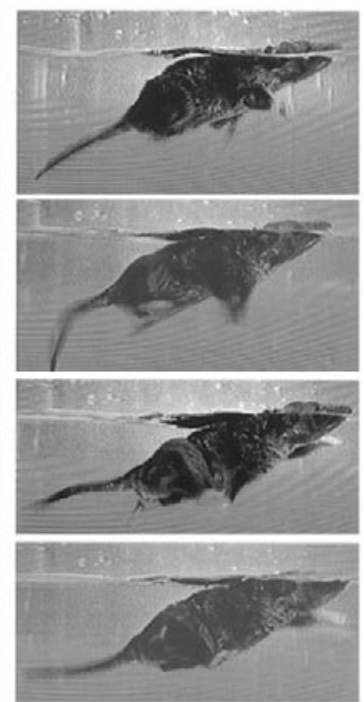

operated

Figure 4. a, Consecutive frames taken from video recordings of climbing in an adult Monodelphis with spinal cord that had been crushed completely at P7 (operated) compared with an unoperated (control) adult. As described in Materials and Methods the animals climbed a narrow beam inclined at $\sim 45^{\circ}$ to the horizontal. The time taken to climb and the number of errors made were recorded. $b$, Consecutive frames taken from video recordings of crossing a $1.5 \mathrm{~cm}$ grid in an adult Monodelphis with spinal cord that had been crushed completely at P7 (operated) compared with an unoperated control adult. As described in Materials and Methods the animals crossed a grid with bars $1.5 \mathrm{~cm}$ apart. The time taken to climb and the number of errors made were recorded (Fig. 5, Tables 3, 4) for the quantitative results of both tests). $c$, Consecutive frames taken from video recordings of swimming in an adult Monodelphis with spinal cord that had been completely crushed at P7 (operated) compared with an unoperated (control) adult. As described in Materials and Methods, animals made seven timed swims in a $1.2 \mathrm{~m}$ tank (Fig. 5, Tables 3, 4).

experimental animals in how long it took to cross either size of grid (Table 3 ) or in the number of mistakes (footfalls through the grid) (Table 3) made in either of the grid sizes. However, in the case of the operated animals, there was a significant difference $(p<0.002)$ in the number of errors made by the hindlimbs compared with the forelimbs; such a difference was not present in the controls (Table 3); this suggests a minor degree of impairment in the lesioned animals. The range of individual performance by all operated and control animals is illustrated in Figure 5.

\section{Runway}

The analysis obtained from footprints (Fig. 2) allowed us to determine the pattern of locomotion for each individual operated and control animal.

From the results of previous studies in rodents we expected to see a decrease in all of the measurements obtained with the exception of the base of support, which increases in animals with spinal cord lesions (Kunkel-Bagden et al., 1993; Bregman et al., 1993). In our experiments there were small decreases in all of the parameters measured, which unexpectedly included a decrease in 

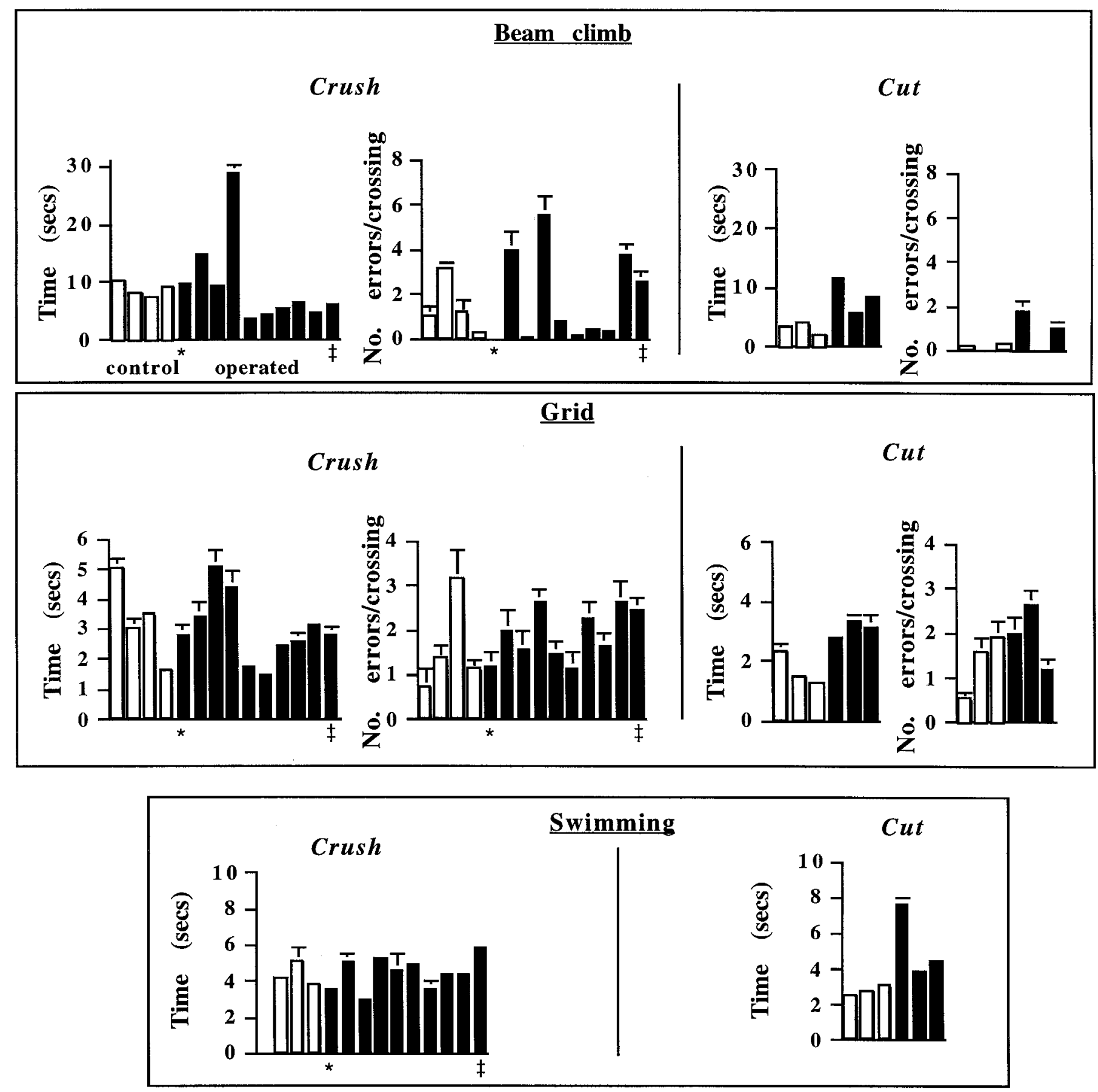

Figure 5. Quantitative results from three of the behavioral tests made in adult animals with spinal cords that been crushed at P7 (left panels) or cut at P4 (right panels) and examined at 6 months of age. Top graphs, Comparison of individual control (open bars) and operated (filled bars) animals in the beam-climbing test (time taken and number of errors); middle panels, crossing the $1.5 \mathrm{~cm}$ grid (time taken and number of errors); bottom panels, Results of the swimming test (time taken to complete distance). Means from 10 trials (7 for swimming test) are shown; error bars indicate 1 SEM; where no bar is shown it was too small to be visible. The mean time for all animals with crush lesions to climb the narrow beam was $9.4 \pm 2.4$ sec, and it was $8.6 \pm$ $0.6 \mathrm{sec}$ in the controls (NS). The mean swimming time for animals with crush lesions was $4,5 \pm 0.3 \mathrm{sec}$, and it was $4.3 \pm 0.4 \mathrm{sec}$ in the controls (NS). For the animals with cut lesions in the swimming test, the mean time for the controls was $2.7 \pm 0.2 \mathrm{sec}$, and for the operated animals it was $5.3 \pm 1.2$ $\sec (\mathrm{NS})$. *Section of spinal cord from this animal are shown in Figure 8f; also compare Figure 6, SFI. ${ }^{\ddagger}$ Sections of spinal cord from this animal are shown in Figure $8 a$. Note that for the tests on the animals with crush lesions, four controls were used except in the swimming test, in which $n=3$, because one of the controls was unable to swim.

the base of support rather than an increase (Table 3). However, in only two of the seven components analyzed in the footprint studies were any of the small differences between control and operated animals statistically significant (Table 3). These were print length $(p<0.005)$ and toe spread $(p<0.05)$. Both of these measurements were shorter in the operated animals than in the controls, and this may indicate that the experimental animals tended to walk on their toes rather than on the whole length of 


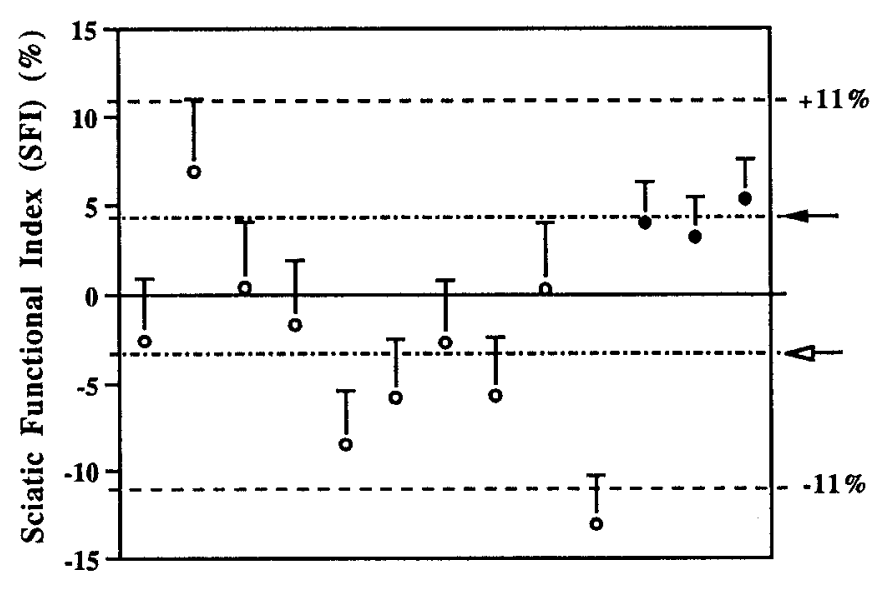

Figure 6. Results from calculation of SFI. The SFI is an estimate of locomotor ability calculated from measurements made in footprint analysis (Fig. 2; see Materials and Methods). The index is considered to be within normal limits if it is within $11 \%$ (note that this is not an SEM) on either side of the control mean. Open circles are mean values for individual animals from 10 trials in adults with spinal cords that had been crushed at P7-P8; filled circles are means of 10 trials for animals with spinal cords cut at P4. Error bars indicate 1 SEM. Mean values for each operated group ( $n=10$ for crush, $n=3$ for cut) are shown by arrows at right; the filled arrow is for cut data, and the open arrow is for crush data. Note that only one animal (with a crush lesion) falls outside of the normal range. The histological appearance of its spinal cord is shown in Figure $8 f$.

the foot. The mean values for rotation, distance to opposite foot, and distance between intermediary toes (see Materials and Methods) were not significantly different between control and crushed animals, and they are not included in Table 3.

As indicated in Materials and Methods, the originally described components of footprint analysis can be used to compute an overall indicator of performance called the SFI. The SFI calculated from our results indicates that all animals except one were within the range of $0 \pm 11 \%( \pm 11 \%$ indicates the range of normality for the SFI; it is not the SEM; see Materials and Methods) (Fig. 6) and were therefore normal with respect to this battery of tests. The one individual that was outside of the normal range was only marginally so, with an SFI of $-13.1 \%$. A section from the spinal cord of this animal is illustrated (see Fig. $8 f$ ).

\section{Swimming, swim plus climb}

Examples of control and operated animals performing this test are illustrated in Figure $4 c$. Results for individual animals are shown in Figure 5. The mean swimming time for animals with crush lesions was $4.5 \pm 0.3 \mathrm{sec}$, and it was $4.3 \pm 0.4 \mathrm{sec}$ in the controls (not significantly different).

There was no measurable time difference between the control and the experimental animals for the swim plus climb test (Table 3).

\section{Behavior of animals 2-6 months after spinal transection (cut)}

Some animals ( $n=19$ from 12 litters) were subjected to cut lesions of the spinal cord at P4-P7. Thirteen of these animals were terminally anesthetized, and their spinal cords were removed for morphological examination. All cords were severed completely (e.g., Fig. 3). The behavior of groups of the remaining animals was observed, and they were then killed by an overdose of anesthetic, after which their spinal cords were removed for morphological examination ( 2 months, $n=3$; 6 months, $n=3$ ). At 3-4 weeks after operation these animals could walk with appar- ent coordination of forelimbs and hindlimbs, but in contrast to control littermates they could not right themselves from a supine to a prone position. However, by 2 months after cutting the animals could walk and run in an apparently normal manner, and they could also right themselves from being placed on their backs. Animals at 6 months after cutting were given the same battery of behavioral tests used for the adult animals with crush lesions (for details of the tests, see above and Materials and Methods). The results obtained from the behavioral testing of these animals are summarized in Table 4. Results from individual animals for several of the tests are shown in Figure 5. As was the case for the older animals with crush lesions (Table 3), many of the differences between control and cut animals were not significantly different; most have therefore not been included in Table 4. There were no significant differences between the control and cut groups in the runway, swimming, and swim plus climb tests (Table 4 and legend to Fig. 5); the SFI (Fig. 6) was within the normal range of $0 \pm$ $11 \%$ for all three operated animals. However, there were significant differences in the time taken to climb the narrow beam and to cross both the 1.5 and $3.5 \mathrm{~cm}$ grids. As was the case for the animals with crush lesions, the Monodelphis with spinal cords that had been cut showed significant differences in grid-crossing performance when errors for hindlimbs and forelimbs were compared, but importantly, the operated individuals could still perform these tasks although not quite as rapidly as the controls. In fact these operated (cut) animals performed as well as the animals with crushed spinal cords, and the differences between operated and controls in the cut group of animals were mainly attributable to the fact that the controls in this group were faster than the controls for the crushed group (compare Tables 3, 4). This was presumably a function of the difference in age of the two groups of animals; i.e., the younger ( 6 months) controls were faster and less inclined to make mistakes than the older (2-3 years) controls.

\section{Morphology of spinal cord lesions at $\mathbf{3}$ months after crush}

At 3 months of age the cross-sectional appearance of the control spinal cords $(n=3)$ resembled that of the adult (compare Figs. $7 a, 8 a)$. In eight animals subjected to complete transection of the cord by crushing at 1 week of age, by 3 months the normal structure of the cord was largely restored, as illustrated in Figure 7, which shows low-power views of transverse or longitudinal sections of the spinal cord from three operated animals and two controls. Two of the cords that had been crushed appear normal (Fig. 7c,e). The other operated cord has an obvious deficit (Fig. $7 b$, arrow) but otherwise appears normal. It is noteworthy that in longitudinal sections through the region of the crush the structure of the cord appeared normal (Fig. 7e).

\section{Morphology of spinal cord in adult opossums after crushing at P7-P8}

Eight adult animals with cords that had been crushed at P7-P8 were examined in serial sections (transverse or longitudinal) stained with silver; they showed substantially normal gross structure. Figure $8 a$ shows the appearance of one of the adult crushed spinal cords in transverse sections above, at, and below the site of the lesion. As was the case for crushed cords at 3 months after operation, in these older animals in most cases the gross appearance of the cord appeared normal, although two cords (one illustrated in Fig. 8a) showed a partial deficit, as was observed in the younger animals with cords that had been crushed (compare Figs. $7 b, 8 a$ ). Figure 8 also shows longitudinal sections (cut serially 


\section{$\underline{3 \text { months }}$}
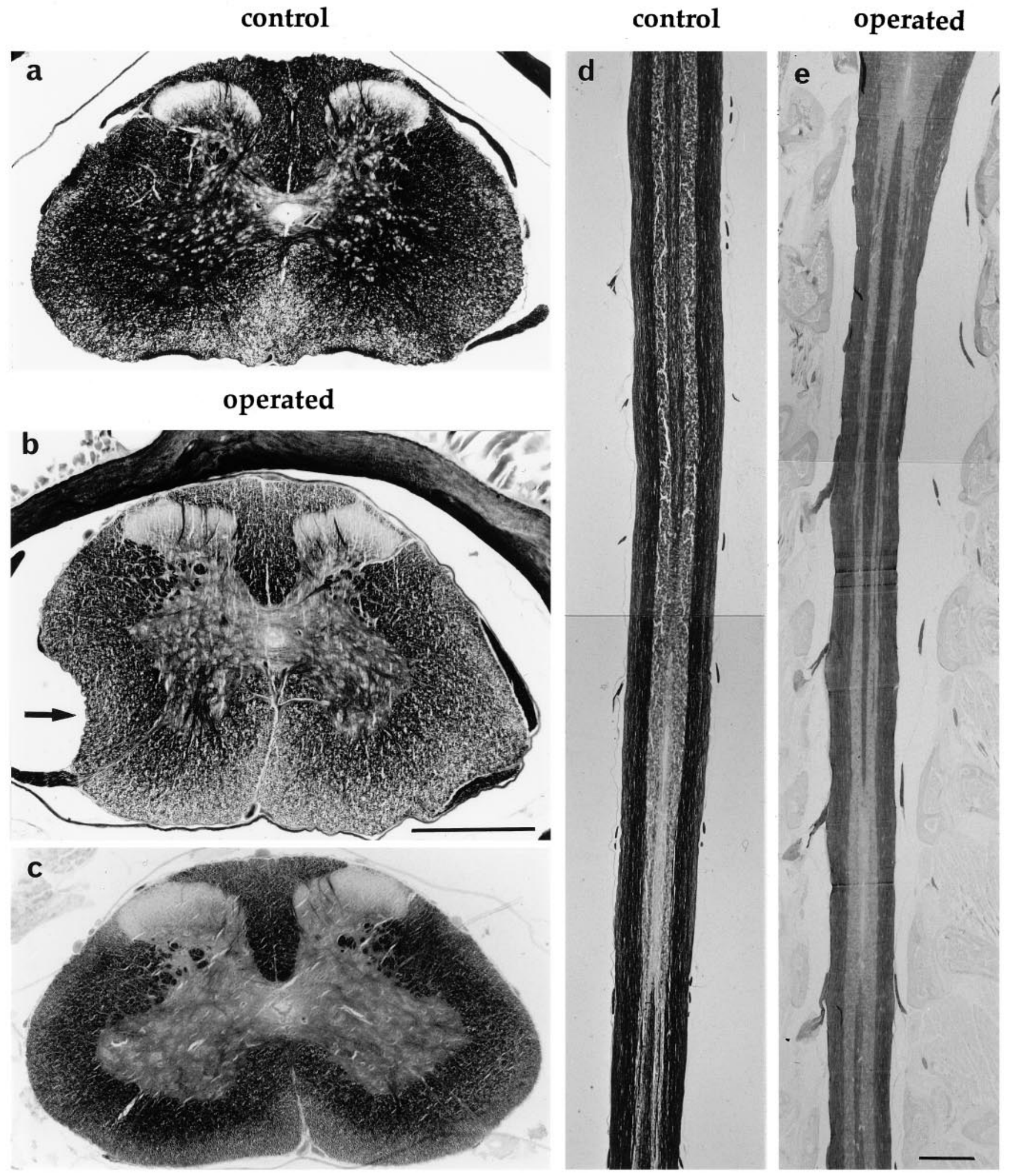

Figure 7. Transverse $(a-c)$ and longitudinal (horizontal) $(d, e)$ silver-stained sections of spinal cords of 3-month-old Monodelphis at the level of a complete crush lesion made at P7-P8. $a$, From an unoperated control. In one animal (b) some deficit in the cross-sectional area was apparent (arrow). Otherwise the structure looked remarkably normal. Scale bar for $a-c, 0.5 \mathrm{~mm}$. $d$, From a control; $e$, from an operated (crush) animal. For these longitudinal sections, the rostral end of the spinal cord is at top. Scale bar for $d, e, 1 \mathrm{~mm}$. Lesions were made at T1-T2. 


\section{$\underline{\text { Adult }}$}

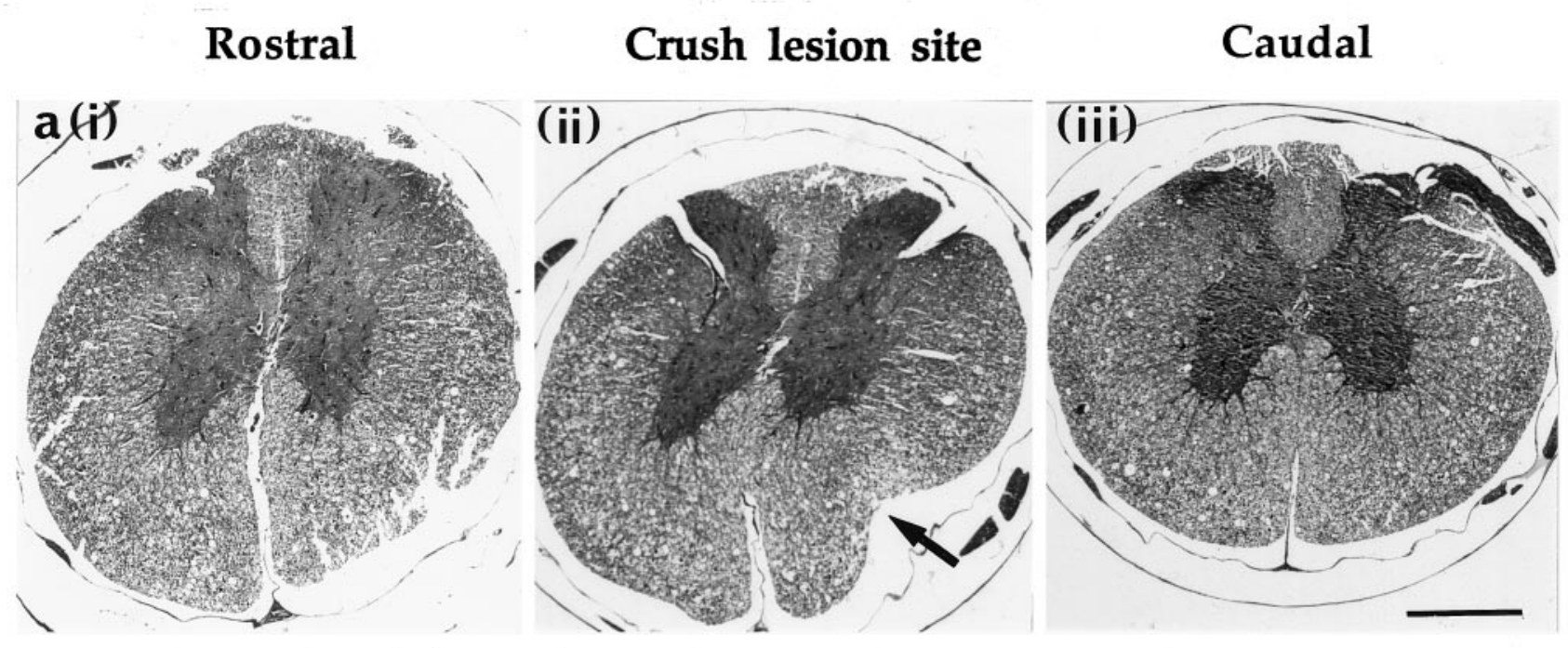

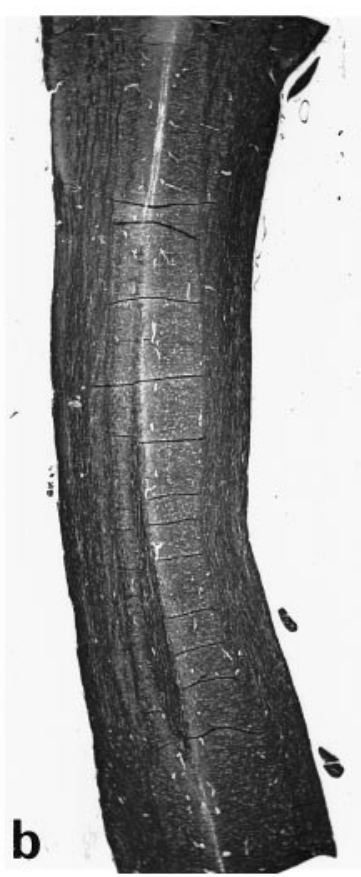

Control
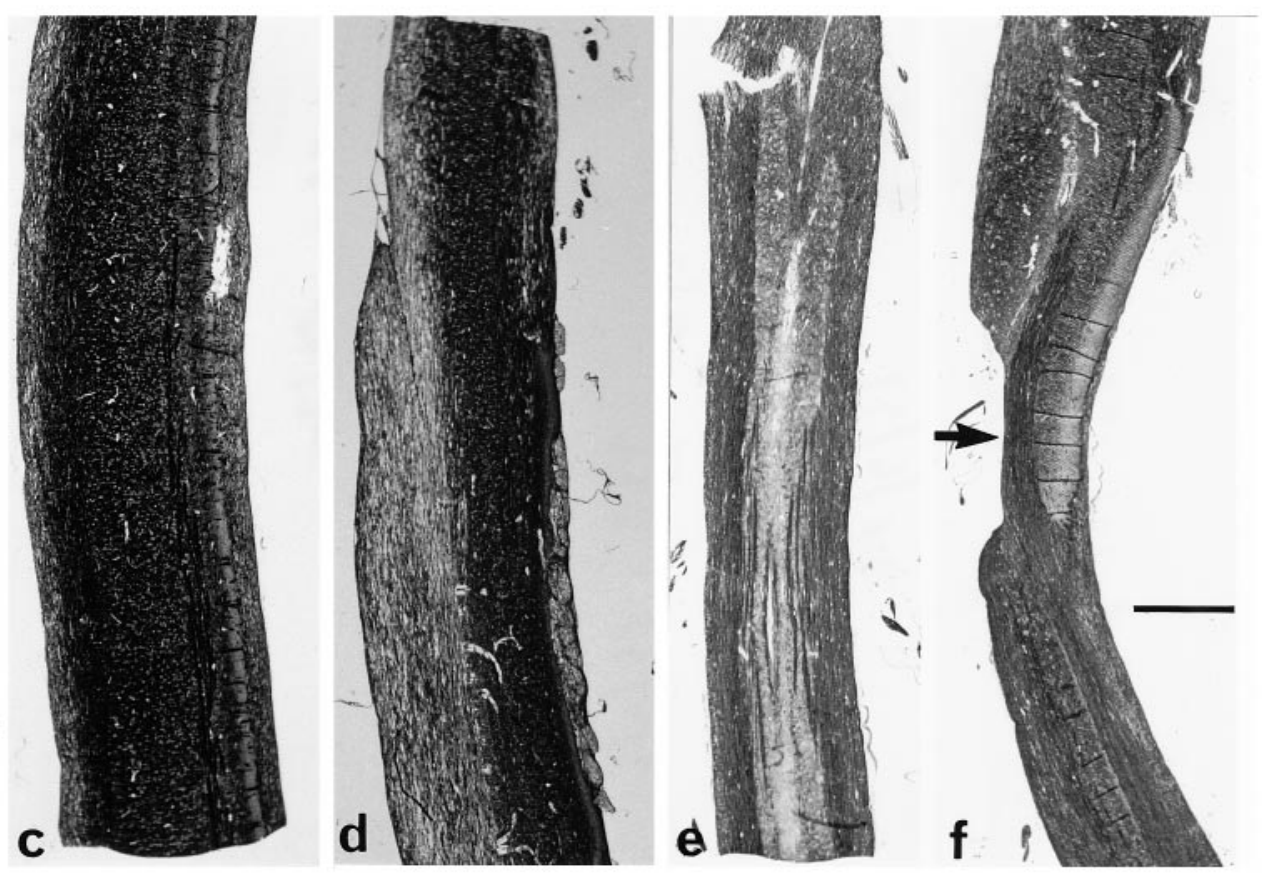

Crush lesion site

Figure 8. Transverse $[a,(i)-(i i i)]$ and longitudinal $(b-f)$ silver-stained sections from the spinal cord of adult Monodelphis that had been completely transected by a crush at P7. a, (i)-(iii) are from the same animal. (i), Rostral to the site of the lesion. (ii), At the level of the lesion (note the structural deficit indicated by the arrow). (iii), Caudal to the site of the lesion. Scale bar in (iii), $0.5 \mathrm{~mm}$; (i) and (ii) are at same scale. Behavioral data for this animal are shown in Figure $5(\stackrel{+}{)}) . b-f$, Longitudinal sections of one control $(b)$ and four operated $(c-f)$ spinal cords of adult Monodelphis that were subjected to complete crushing of the cord (T1-T2) at P7-P8. In $f$ there is an obvious deficit (arrow) in the gross structure, which correlated with a greater degree of impaired function on behavioral testing (this is the spinal cord from the only animal with a sciatic function index that was outside of the normal limits (Fig. 6). Scale bar in $f, 1 \mathrm{~mm} ; b-e$ are at same scale. 

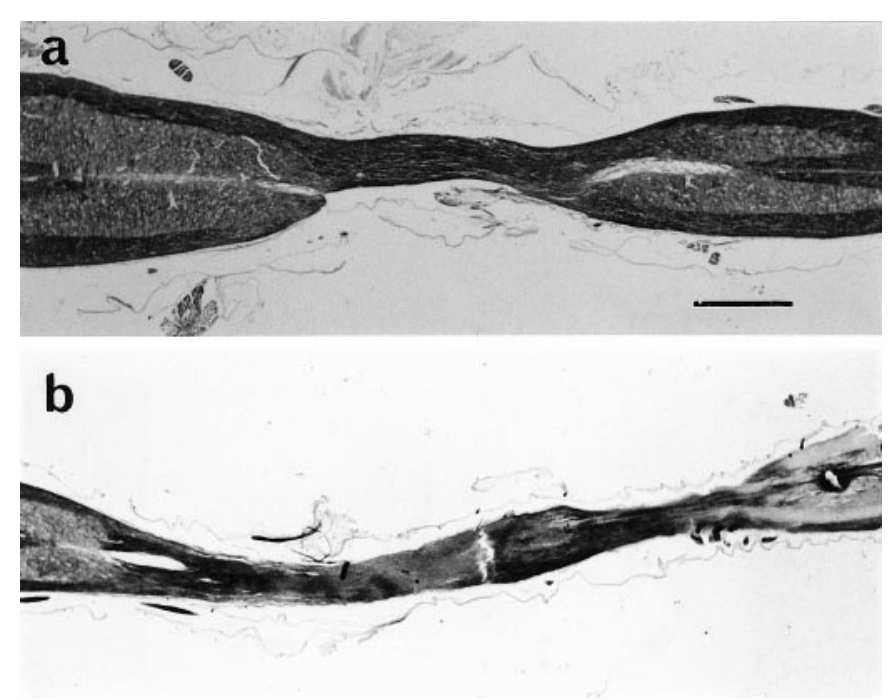

Figure 9. Longitudinal sections of two 6-month-old Monodelphis with spinal cords that had been transected completely by a cut (T1-T2) at P4. Note the considerable narrowing of the spinal cords at the site of the lesion; there is an artifactual break in section $b$. Numerous nerve fibers cross the site of the original lesion. Scale bar, $1 \mathrm{~mm}$.

from dorsal to ventral surfaces) from one control (Fig. $8 b$ ) and from four spinal cords that had been crushed at P7-P8 (Fig. 8c-f). One of these (Fig. $8 f$ ) showed a partial deficit. This animal was the only one with an abnormal SFI (Fig. 6).

The longitudinal sections show clearly that numerous nerve fibers (including many myelinated fibers) extended in well organized tracts, which spanned the length of the cord examined, including the site of the original lesion. At higher magnification in transverse sections there were mature-looking anterior horn cells with motor axons extending to form the ventral roots leaving the cord (results not shown).

\section{Morphology of spinal cord after cut lesions}

The spinal cords of animals that had been transected completely by cutting and were examined morphologically at 2 months (results not shown) or 6 months (Fig. 9) after the operation showed more obvious deficits in gross structure than the cords of 3 month or adult animals with crush lesions made in the neonatal period (compare Figs. 7-9). In the animals with cords that had been cut, the cord was clearly thinned at the site of the original lesion, as illustrated in Figure 9. The appearance of the spinal cord lesion sites in the three animals studied at 2 months after cutting was similar.

\section{Conduction through lesioned spinal cord}

To test for restoration of conduction after recovery and growth to adulthood, stimuli were applied to five animals 2-3 years after the spinal cord had been crushed and to three controls of similar age. The operated and control animals had been tested behaviorally before the experiment. The records of Figure 10 show volleys recorded in the spinal cord above the lesion and in the cerebral cortex after stimulation of the sciatic nerve. The recording electrode was moved over the exposed cortical surface to obtain a maximal signal amplitude. The traces were very similar in operated animals and in controls. Differences such as those that occurred could be attributed to slight variations in the placement of the recording electrode; movements of 1-2 $\mathrm{mm}$ produced, as expected, changes in amplitude and configuration. Similar traces were recorded from the sciatic nerve when stimuli were applied to the cortex or the spinal cord above the lesion (data not shown). Acute transection of the cord rostral or caudal to the chronic lesion abolished all conduction of signals such as those shown in Figure 10.

\section{Neural pathways in adults across the site of a cord lesion made at P5-P7}

To obtain morphological evidence of the contribution of supraspinal neurons to the population of fibers crossing the site of the lesion, pathway-labeling experiments using dextran amine were performed in animals with spinal cords that had been lesioned in the first week of life. Four animals with spinal cords that had been crushed or cut in the neonatal period were reanesthetized and received injections into the spinal cord of dextran amine, as described in Materials and Methods; two control animals were used for comparison. Seven days after an injection distal to the site of the lesion, the animals were terminally anesthetized, and brains and spinal cords were fixed. The distribution of fluorescent-labeled neurons was mapped in serial sagittal sections through brain stem and midbrain as described in Materials and Methods. Figure 11 shows composite camera lucida drawings obtained from the serial sections from a control animal and an operated animal. Several clearly delineated nuclei could be seen (Fig. 11). As shown in Figure 11, regions with neurons retrogradely labeled with dextran amine-Fluororuby included midbrain central gray, nucleus Darkschewitsch, dorsal medullary reticular field, Edinger Westphal nucleus, gigantocellular reticular nucleus, intermediate medullary reticular field, interstitial nucleus of the medial longitudinal fasciculus, locus coeruleus, lateral tegmental area, lateral vestibular nucleus, raphe magnus, red nucleus, and the ventral medullary reticular nucleus. The micrograph in Figure 11, inset, shows an example of the appearance of retrogradely labeled neurons, in this case in the lateral vestibular nucleus.

\section{DISCUSSION}

\section{Morphology and functional recovery of adult spinal cord lesioned at P4-P8}

In most 3-month-old and adult animals with spinal cords that had been completely crushed when newborn, the gross structure of the spinal cord appeared remarkably normal. A few had an obvious defect at the lesion site (Figs. $7 b, 8 a, f$, arrows). In only two components of the runway test were there statistically significant differences between the control and operated animals; the overwhelming impression was that these animals were nearly normal (Table 3). Only one showed any visually obvious or statistically significant behavioral deficits that correlated with a structural deficit (compare Figs. 6, 8f). Electrophysiological testing of the animals gave clear evidence of impulse conduction in both directions across the lesion (Fig. 10). This, coupled with evidence from dextran amine pathway-tracing experiments (Fig. 11 and next section), indicates that the morphological repair at the site of the injury was accompanied by significant functional recovery that involved development of supraspinal connections.

Neonates with cut lesions of the spinal cord (Fig. 9), showed less morphological recovery and growth of the cord and more impaired behavior than after crushing (Figs. 7, 8). This is hardly surprising, because the pia mater, which normally provides a pathway for growth, has been severed (Varga et al., 1996); moreover, a greater separation occurs between the two segments of spinal cord after a cut. The principal reason for making cuts in 
SCIATIC TO SPINAL CORD
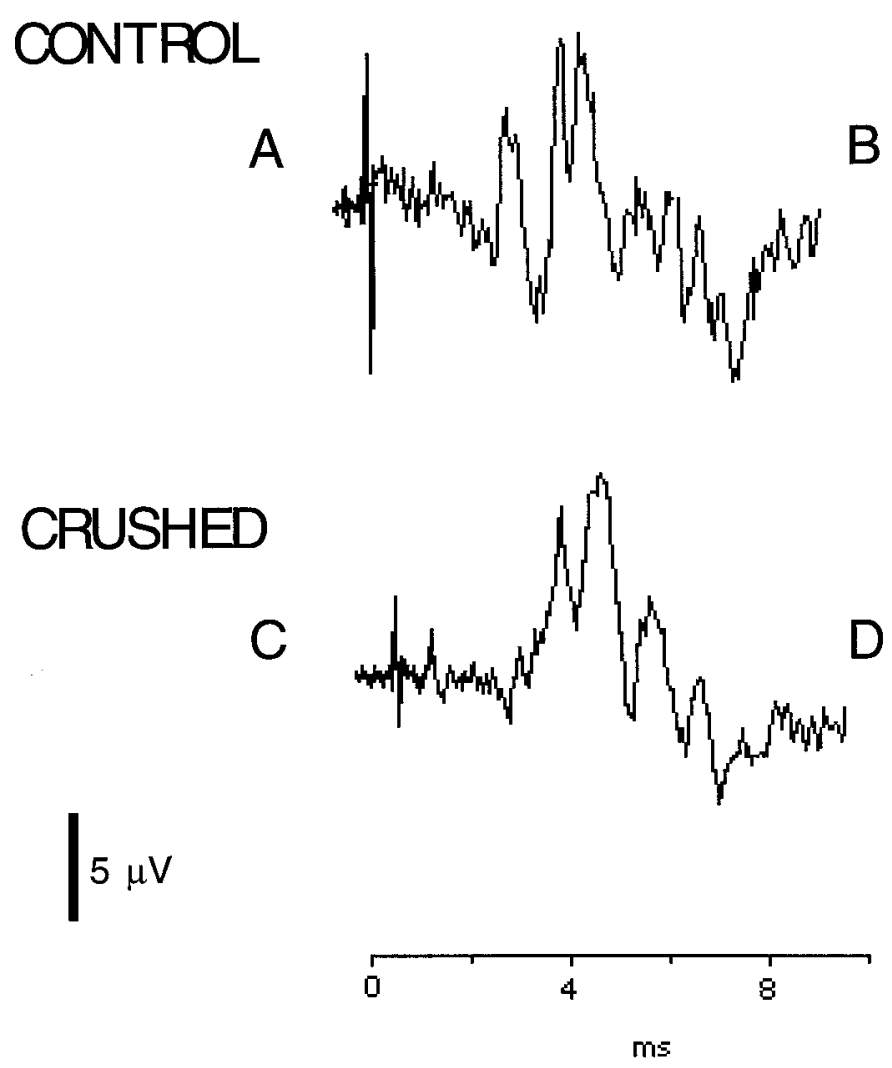

SCIATIC TO CORTEX
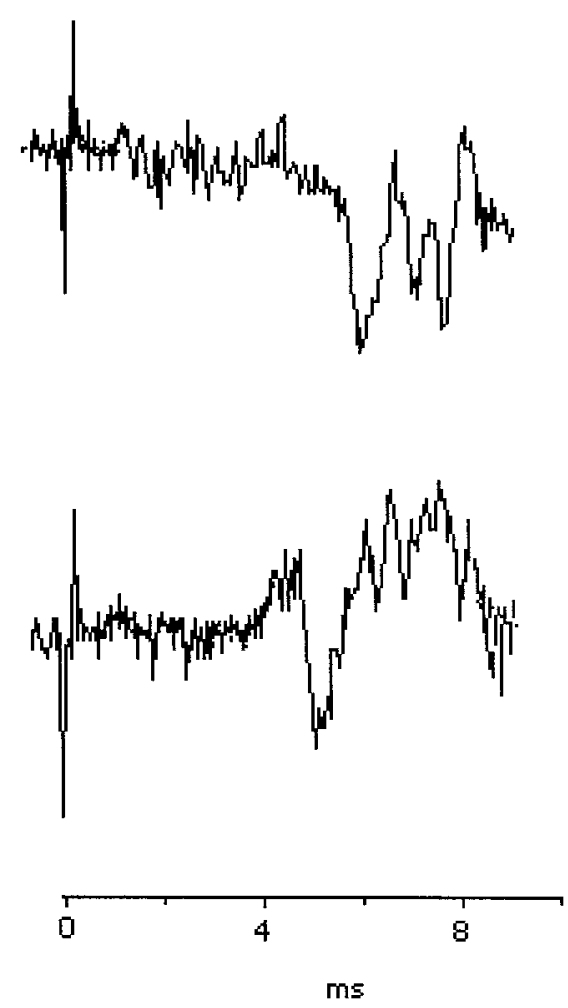

Figure 10. Electrophysiological recordings in an anesthetized adult Monodelphis with spinal cord crush made at P7 $(C, D)$ compared with an anesthetized control adult $(A, B)$. Recording conditions were as described in Materials and Methods. In $A$ and $C$ the stimulating electrodes were placed on the sciatic nerve with recording electrodes on the spinal cord. In $B$ and $D$ the recording electrodes were moved to the sensory cortex. Similar records were obtained in all five operated and three control (unoperated) animals that were tested for impulse conduction across the site of the crush lesion.

addition to crushes was to establish unequivocally the completeness of transection of all fibers. Most of our studies involved crushes, because there is a greater delay in outgrowth of fibers after cutting; this is more complex to analyze, because the ability of the spinal cord to support the outgrowth of new axons declines with age (see Varga et al., 1995a).

Recovery occurred in animals with both types of lesion without implants of fetal spinal cord, as used in neonatal rats (e.g., Bregman et al., 1993; Iwashita et al., 1994). The latter study is one of the few in which substantial functional recovery was reported after a complete lesion of the spinal cord; however, their data are insufficiently comprehensive or quantitatively described for it to be clear how well these neonatal rats compare with our neonatal opossums. In our study, presumably because of the greater immaturity of the opossum neonatal spinal cord compared with that of the neonatal rat, recovery and growth occurred without any fetal implant. Miya et al. (1997) published a more detailed report of similar experiments in neonatal rats and found that there were greater behavioral differences between control and operated animals when adult than in our studies of the opossum. Also in their rat studies, the morphological repair appears to have been both less substantial and more variable.

A preliminary report of the structure of the spinal cord of Monodelphis at P3-P8 has been published (Møllgård et al., 1994). A more detailed description is in preparation (G. W. Knott and P. Kitchener, unpublished data). From these studies it is clear that the stage of development of the P4-P8 Monodelphis cord is similar to the E12-E13 chick embryo spinal cord (see Hasan et al., 1993), although the developmental timetable seems to be appreciably faster in the chick.

\section{New growth and regeneration}

Injection of dextran amine caudal to the lesion with subsequent examination of brainstem and midbrain (Fig. 11) in four lesioned animals compared with two controls revealed retrogradely labeled neurons in many nuclei shown previously to project to the spinal cord in Monodelphis (Holst et al., 1991; Wang et al., 1992). Development of descending projections to the spinal cord by retrograde tracing using fast blue injections into cervical or lumbar regions has been described by Wang et al. (1992). All major brainstem and midbrain nuclei that make descending projections in the adult (including medullary and pontine reticular nuclei, lateral, medial, and inferior vestibular nuclei, the locus coeruleus, and the red nucleus) were labeled by both cervical and lumbar injections in P7 pups (some were labeled as early as P0). In contrast, the corticospinal and colliculospinal projections were not labeled retrogradely by cervical or lumbar injections made at P14 or earlier. This indicates that the red nucleus and brainstem nuclei have made substantial projections, even as far as lumbar segments, by the time we made spinal lesions (P7), but colliculospinal and corticospinal projections have not yet reached the spinal cord at this time. However, the possibility that some descending projections from 


\section{OPERATED}

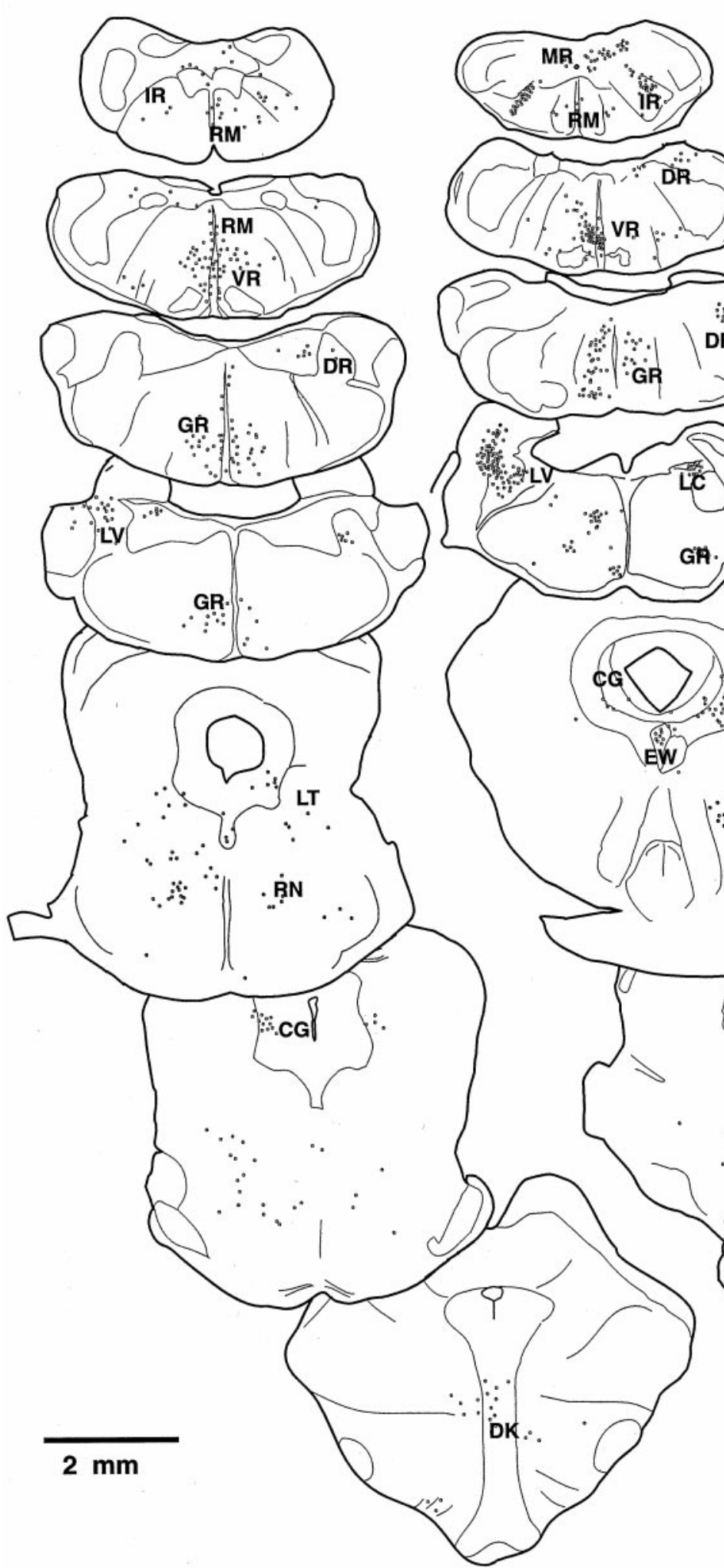

CONTROL

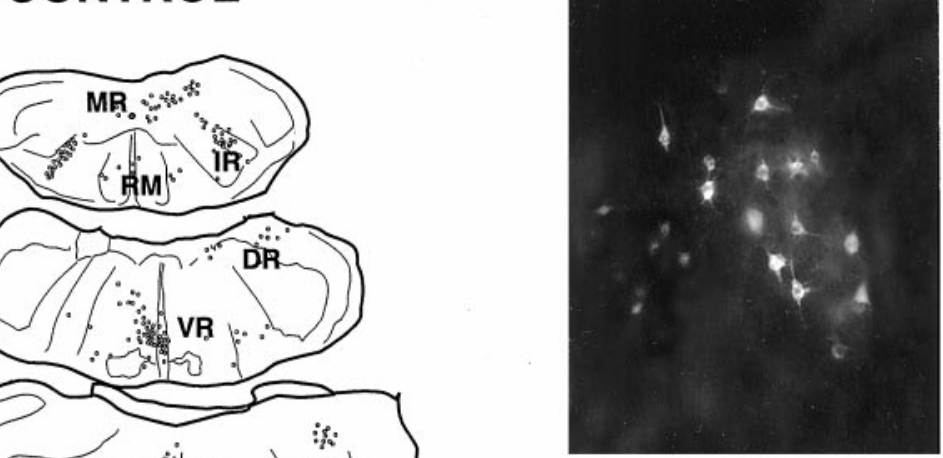

OPERATED

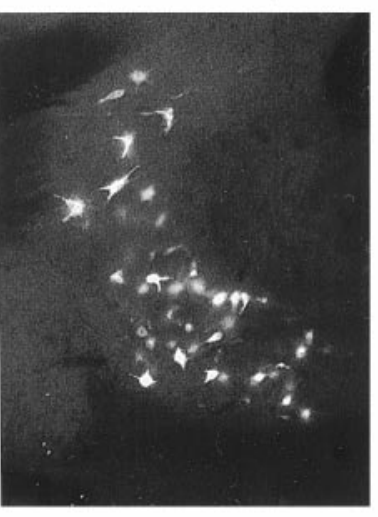

CONTROL

Figure 11. Spaced serial coronal sections showing the location of brainstem and midbrain neurons retrogradely labeled after injection of Fluororuby dextran amine into the lumbar spinal cord of adult Monodelphis. The series on the left is from an animal in which the spinal cord was crushed on P7; on the right is an unoperated control. Inset, Micrographs show retrogradely labeled neuronal somata in the lateral vestibular nucleus ( $L V$ ). Magnification, $5 \times$ bar). $C G$, Midbrain central gray; $D K$, nucleus Darkschewitsch; $D R$, dorsal medullary reticular field; $E W$, Edinger Westphal nucleus; $G R$, gigantocellular reticular nucleus; $I R$, intermediate medullary reticular field; $I N$, interstitial nucleus of the medial longitudinal fasciculus; $L C$, locus coeruleus; $L T$, lateral tegmental area; $R M$, raphe magnus; $R N$, red nucleus; $V R$, ventral medullary reticular nucleus. 
brainstem and the red nucleus are also made after P7 cannot be ruled out. Consequently, any fiber growth across the site of the lesion is likely to have been a mixture of regeneration from injured axons and growth of new axons that were not present at that level of the spinal cord at the time of making the lesion.

Martin and colleagues have obtained evidence similar to that presented in this paper for growth of axons across a spinal cord lesion made in the early neonatal period in Didelphis (Terman et al., 1996; Wang et al., 1996, 1997), but they were also not able to distinguish between regeneration and growth of new fibers. By direct visualization of injured axons in isolated neonatal Monodelphis CNS preparations, Varga et al. (1995b) were able to demonstrate regeneration of dorsal root fibers and axons in ventral spinal cord tracts. From double-labeling studies after spinal lesions in chick embryos (Hasan et al., 1993), neonatal opossums (Xu and Martin, 1991), and neonatal rats with implanted fetal CNS (Bernstein-Goral and Bregman, 1993), it was concluded that fiber growth across the lesion was a mixture of new fibers and regeneration. In our studies it is also likely that new growth and regrowth combined to produce a spinal cord that appeared normal at the site of the lesion, particularly after crushing at P7-P8.

\section{Mechanism of functional recovery after a complete spinal cord lesion at P4-P8}

Adult mammals with complete spinal transections do not show any signs of anatomical or functional repair of the lesion; however, they can, if adequate balance is maintained, walk unsupported on treadmills; they can also compensate for treadmill speed changes and perturbations in the ground over which they walk (see Grillner and Wallen, 1985). Thus lumbar spinal cord and afferent inputs can act as a locomotor system independent of supraspinal control. In the interpretation of our behavioral data on neonatally lesioned Monodelphis, the argument could be made that the lumbar spinal cord, isolated from the rest of the nervous system from $\mathrm{P} 4-8$ by the cut or crush lesions, may function as an independent locomotor system. Our observations of swimming, climbing, and grid crossing in adults lesioned at P4-P8 suggest that supraspinal mechanisms must be involved in these movements; thus in our experiments the hindlimbs were activated to produce locomotion, which itself requires intact spinocerebellar ascending connections and intact rubrospinal, reticulospinal, and vestibulospinal tracts (Arshavsky et al., 1983); climbing would have required both interlimb coordination and intact vestibulospinal tracts. This interpretation of the behavioral observations is supported by the results of the electrophysiological (Fig. 10) and dextran amine pathway-tracing experiments (Fig. 11).

We were unsuccessful in establishing an upper limit to the period when fiber growth still follows injury in postnatal Monodelphis in vivo. This was because of extensive cannibalism by the mothers. In this respect, Didelphis may be a more favorable model, because the young are protected by the pouch in contrast to the vulnerability of the young of the pouchless Monodelphis. However, it is clear from the in vitro (Varga et al., 1995a) and in vivo (MacLaren and Taylor, 1995) experiments with Monodelphis, as well as in the in vivo studies in Didelphis (Terman et al., 1996; Wang et al., 1996), that in our animals a marked decline in fiber outgrowth after a spinal cord lesion would be expected to occur in lesions of the upper thoracic cord made after $\sim$ P12-P14.

\section{Establishment of functionally effective connections}

We have not in this study attempted to answer the question of whether the connections made by axons that have grown through the lesion are normal or whether the animals cope with abnormal connections by learning how to use them. Interspecies comparisons suggest that the processes of fiber growth after injury and reaching appropriate targets may be evolutionarily separable; this is suggested by work of Beazley et al. (1997), which showed that after lesioning of the optic nerve in lizards, although regenerating fibers crossed the lesion, unlike in amphibians, the fibers failed to find functionally effective targets. Thus if it can be shown in Monodelphis in vivo that fibers growing through a lesion are able to reach normal targets, then this species will be invaluable for studying that process in addition to providing a model for fiber growth across a lesion in the spinal cord. An indication that this is so comes from recent in vitro Monodelphis studies showing that regenerating dorsal root axons grow toward and terminate on motoneurons (M. Lepre and J. G. Nicholls, unpublished results).

\section{Implications for spinal repair in adults}

It is likely that changes in the spinal cord between an early developmental stage when fiber growth and functional recovery occur and the stage when this does not happen are complex (cf. Fawcett, 1992). In vitro studies (Varga et al., 1995a,b) suggest that onset of expression of inhibitory factors described by Schwab and Bartholdi (1996) and Keirstead et al. (1992) in other species occurs at P12-P14 in the lower cervical region of the cord of Monodelphis. Morphological, including immunocytochemical, studies of the developing spinal cord of this species confirm that oligodendroglia have appeared by this age (Møllgård et al., 1994; Varga et al., 1995a). However, there are likely to be other factors that are expressed and still others that are downregulated as part of normal development that are influencing the capacity of the injured immature spinal cord to repair itself and to develop normally. An important question is to what extent these changes can be identified, and if they are so identified, whether they can be re-expressed or in the case of inhibitory influences downregulated in the injured adult spinal cord, so that some degree of repair might then occur.

\section{REFERENCES}

Aguayo AJ, Rasminsky M, Bray GM, Carbonetto S, McKerracher L, Villegas-Perez MP, Vidal-Sanz M, Carter DA (1991) Degenerative and regenerative responses of injured neurons in the central nervous system of adult mammals. Philos Trans R Soc Lond [Biol] 331:337-343.

American Paralysis Association (1994) Research program and guidelines. Springfield, NJ: American Paralysis Association.

Armstrong JR, Ferguson MWJ (1995) Ontogeny of the skin and transition from a scar-free to a scarring phenotype during wound healing in the pouch young of a marsupial Monodelphis domestica. Dev Biol 169:242-260.

Arshavsky Y, Gelfland IM, Orlovsky GN (1983) The cerebellum and control of rhythmical movements. Trends Neurosci 6:417-422.

Bates CA, Stelzner DJ (1993) Extension and regeneration of corticospinal axons after early spinal injury and the maintenance of corticospinal topography. Exp Neurol 123:106-117.

Beazley LD, Sheard PW, Tennant M, Starac D, Dunlop SA (1997) Optic nerve regenerates but does not restore topographic projections in the lizard Ctenophorus ornatus. J Comp Neurol 377:105-120.

Bergallo HG, Cerqueira R (1994) Reproduction and growth of the opossum Monodelphis domestica (Mammalia: Didelphidae) in northeastern Brazil. J Zool 232:551-563.

Bernstein DR, Stelzner DJ (1983) Plasticity of the corticospinal tract following midthoracic spinal injury in the postnatal rat. J Comp Neurol 221:382-400.

Bernstein-Goral H, Bregman BS (1993) Spinal cord transplants support the regeneration of axotomized neurons after spinal cord lesions at birth: a quantitative double-labelling study. Exp Neurol 123:118-132.

Bregman BS, Goldberger ME (1983a) Infant lesion effect: I. Development of motor behaviour following neonatal spinal cord damage in cats. Dev Brain Res 9:103-117. 
Bregman BS, Goldberger ME (1983b) Infant lesion effect: II. Sparing and recovery of function after spinal cord damage in newborn and adult cats. Dev Brain Res 9:119-135.

Bregman BS, Kunkel-Bagden E, Reier PJ, Dai HN, McAtee M, Gao D (1993) Recovery of function after spinal cord injury: mechanisms underlying transplant-mediated recovery of function differ after spinal cord injury in newborn and adult rats. Exp Neurol 123:3-16.

Cheng H, Cao Y, Olson L (1996) Spinal cord repair in adult paraplegic rats: partial restoration of hind limb function. Science 273:510-513.

de Medinaceli L, Freed WJ, Wyatt RJ (1982) An index of the functional condition of rat sciatic nerve based on measurements made from walking tracks. Exp Neurol 77:634-643.

Fadem BH, Trupin GL, Maliniak E, VandeBerg JL, Hayssen V (1982) Care and breeding of the grey, short-tailed opossum (Monodelphis domestica). Lab Anim Sci 32:405-409.

Fawcett JW (1992) Intrinsic neuronal determinants of regeneration. Trends Neurosci 15:5-8.

Goldberger ME, Bregman BS, Vierck CJ, Brown M (1990) Criteria for assessing recovery of function after spinal cord injury: behavioural methods. Exp Neurol 107:113-117.

Grillner S, Wallen IG (1985) Central pattern generators for locomotion, with special reference to vertebrates. Annu Rev Neurosci 8:233-261.

Hasan SJ, Keirstead HS, Muir GD, Steeves JD (1993) Axonal regeneration contributes to repair of injured brainstem spinal neurons in embryonic chicken. J Neurosci 13:492-507.

Holst M-C, Ho RH, Martin GF (1991) The origins of supraspinal projections to lumbosacral and cervical levels of the spinal cord in the grey short-tailed Brazilian opossum, Monodelphis domestica. Brain Behav Evol 38:273-289.

Iwashita Y, Kawaguchi S, Murata M (1994) Restoration of function by replacement of spinal cord segments in the rat. Nature 367:167-170.

Keirstead HS, Hasan SJ, Muir GD, Steeves D (1992) Suppression of the onset of myelination extends the permissive period for the functional repair of embryonic spinal cord. Proc Natl Acad Sci USA 89:11664-11668.

Krause WJ, Saunders NR (1994) Brain growth and neocortical development in the opossum. Ann Anat 176:395-407.

Kunkel-Bagden E, Bregman BS (1990) Spinal cord transplants enhance the recovery of locomotor function after spinal cord injury at birth. Exp Brain Res 81:25-34.

Kunkel-Bagden E, Dai H-N, Bregman BS (1992) Recovery of function after spinal cord hemisection in newborn and adult rats: differential effects on reflex and locomotor function. Exp Neurol 116:40-51.

Kunkel-Bagden E, Dai H-N, Bregman BS (1993) Methods to assess the development and recovery of locomotor function after spinal cord injury in rats. Exp Neurol 119:153-164.

MacLaren RE, Taylor JSH (1995) A critical period for axon regrowth through a lesion in the developing mammalian retina. Eur J Neurosci 7:2111-2118.

Martin GF, Xu XM (1988) Evidence of developmental plasticity of the rubrospinal tract. Studies using the North American opossum. Dev Brain Res 39:303-308.

Miya M, Giszter S, Mori F, Adipudi V, Tessler A, Murray M (1997) Fetal transplants alter the development of function after spinal cord transection in newborn rats. J Neurosci 17:4856-4872.

Møllgård K, Balslev Y, Stagaard JM, Treherne JM, Saunders NR, Nicholls JG (1994) Development of spinal cord in the isolated CNS of a neonatal mammal (the opossum Monodelphis domestica) maintained in longterm culture. J Neurocytol 23:151-165.

Nicholls J, Saunders N (1996) Regeneration of immature mammalian spinal cord after injury. Trends Neurosci 19:229-234.

Nicholls JG, Stewart RR, Erulkar SD, Saunders NR (1990) Reflexes, fictive respiration and cell division in the brain and spinal cord of the newborn opossum, Monodelphis domestica, isolated and maintained in vitro. J Exp Biol 152:1-15.

Rossignol S (1996) Neural control of stereotypic limb movements. In Handbook of physiology, Sec 12, Chap 5 (Rowell LB, Shepherd JTS, eds), pp 173-216. Oxford: Oxford UP.

Saunders NR (1997) Marsupials as models for studies of development and recovery from injury of the central nervous system. In: Marsupial biology: recent research, new perspectives (Saunders NR, Hinds L, eds), pp 382-410. Sydney, Australia: University of New South Wales.

Saunders NR, Adams E, Reader M, Møllgård K (1989) Monodelphis domestica (grey short-tailed opossum): an accessible model for studies of early neocortical development. Anat Embryol 180:227-236.

Saunders NR, Balkwill P, Knott G, Habgood MD, Møllgård K, Nicholls JG, Treherne JM (1992) Growth of axons through a lesion in the intact CNS of fetal rat maintained in long-term culture. Proc R Soc Lond [Biol] 250:171-180.

Saunders NR, Weller L, Deal A, Knott GW (1994) Recovery from spinal cord injury in neonatal South American opossums. Soc Neurosci Abstr 20:520.9.

Saunders NR, Deal A, Knott GW, Varga ZM, Nicholls JG (1995) Repair and recovery, following spinal cord injury in a neonatal marsupial (Monodelphis domestica). Clin Exp Pharmacol Physiol 22:518-526.

Schwab ME, Bartholdi D (1996) Degeneration and regeneration of axons in the lesioned spinal cord. Physiol Rev 76:319-370.

Shimizu I, Oppenheim RW, O’Brien M, Shneiderman A (1990) Anatomical and functional recovery following spinal cord transection in the chick embryo. J Neurobiol 21:918-937.

Sievers AC, Munger BL (1965) A silver stain for paraffin sections of neural tissue. J Neuropathol Exp Neurol 24:130-135.

Terman JR, Wang XM, Martin GF (1996) Growth of dorsal spinocerebellar axons through a lesion of their spinal pathway during early development in the North American opossum, Didelphis virginiana. J Comp Neurol 93:33-48.

Treherne JM, Woodward SKA, Varga ZM, Ritchie JM, Nicholls JG (1992) Restoration of conduction and growth of axons through injured spinal cord of neonatal opossum in culture. Proc Natl Acad Sci USA 89:431-434.

Varga ZM, Bandtlow CE, Erulkar SD, Schwab ME, Nicholls JG (1995a) The critical period for repair of CNS of neonatal opossum (Monodelphis domestica) in culture: correlation with development of glial cells, myelin and growth-inhibitory molecules. Eur J Neurosci 7:2119-2129.

Varga ZM, Schwab ME, Nicholls JG (1995b) Myelin-associated neurite growth-inhibitory proteins and suppression of regeneration of immature mammalian spinal cord in culture. Proc Natl Acad Sci USA 92:10959-10963.

Varga ZM, Fernandez J, Blackshaw S, Muller KJ, Adams WB, Nicholls JG (1996) Neurite outgrowth through lesions of neonatal opossum spinal cord in culture. J Comp Neurol 366:1-13.

Wang XM, Xu XM, Qin YQ, Martin GF (1992) The origins of supraspinal projections to the cervical and lumbar spinal cord at different stages of development in the grey short-tailed Brazilian opossum, Monodelphis domestica. Dev Brain Res 68:203-216.

Wang XM, Terman JR, Martin GF (1996) Evidence for growth of supraspinal axons through the lesion after transection of the thoracic spinal cord in the developing opossum, Didelphis virginiana. J Comp Neurol 371:104-115.

Wang XM, Qin YQ, Terman JR, Martin GF (1997) Early development and plasticity of the fasciculus gracilis in the North American opossum (Didelphis virginiana). Dev Brain Res 98:151-163.

Xu XM, Martin GF (1991) Evidence for new growth and regeneration of cut axons in developmental plasticity of the rubrospinal tract in the North American opossum. J Comp Neurol 313:103-112. 